\title{
Espectadoras privilegiadas en la convivencia de María de Mendoza y su hija María Sarmiento con las comunidades religiosas de su patronato
}

\section{Privileged viewers in the coexistence of María de Mendoza and her daughter María Sarmiento with the religious communities under their patronage}

\author{
Sergio Ramiro Ramírez \\ Universidad Complutense de Madrid
}

Fecha de recepción: 13 de julio de 2017

Fecha de aceptación: 31 de mayo de 2018

\begin{abstract}
RESUMEN
Con el aumento en el número de patronatos nobiliarios sobre monasterios y capillas funerarias durante el siglo XVI, las familias patrocinadoras se aseguraron lugares privilegiados desde los que asistir a los oficios religiosos en la iglesia, generalmente tribunas o habitaciones provistas de vanos que permitiesen una correcta visualización del altar mayor. En este artículo se analizan los problemas de convivencia que se produjeron a la hora de conciliar los intereses de ambas partes y como estas preeminencias tuvieron su impacto en la arquitectura de estos edificios. Con este objetivo se estudia la influencia de la vida conventual en María de Mendoza (1508-1587) y su hija María Sarmiento (1526-1604), las cuales transformaron sus propias casas en establecimientos religiosos.
\end{abstract}

\section{PALABRAS CLAVE}

Siglo XVI. Patronazgo. Fundación conventual. Tribunas. María de Mendoza. Teresa de Jesús. Nuestra Señora de la Piedad de Granada.
Anuario del Departamento de Historia y Teoría del Arte
vol. 29-30, 2017-2018, pp. 123-142
ISSN: 1130-5517, eISSN: 2530-3562

http://doi.org/10.15366/anuario2017-2018.29-30.05

\section{KEY WORDS}

$16^{\text {th }}$ Century. Patronage. Monastery Foundation. Galleries. María de Mendoza. Teresa de Jesús. Nuestra Señora de la Piedad in Granada. 


\section{Las tribunas regias y la expansión de su uso a la aristocracia ${ }^{1}$}

Los monarcas hispanos y sus familias usaron de manera habitual conventos y monasterios para hospedarse junto a su corte, al tiempo que crearon sus propios cuartos reales dentro de diferentes complejos monacales ${ }^{2}$. Un punto de inflexión en la evolución y difusión de esa práctica lo representan las promociones arquitectónicas de Isabel la Católica en edificios de patronato real como el monasterio de Guadalupe, el Abrojo en Valladolid $^{3}$, el Parral de Segovia, Santo Tomás de Ávila, San Juan de los Reyes y la Catedral Primada en Toledo $^{4}$, o San Jerónimo de Madrid ${ }^{5}$. Un hábito que comportó la puesta en marcha de un significativo número de iniciativas que tuvieron su continuación, de manera forzosa, en la reclusión de su hija Juana I en Tordesillas ${ }^{6}$.

Las mujeres de la Casa de Austria perpetuaron esta cercanía con las instituciones conventuales convertidas transitoriamente en capillas áulicas ante la presencia de las reales dignidades. Cuando la emperatriz se aposentó en residencias de titularidad nobiliaria que no contaban con la infraestructura necesaria para procurarle el acceso desde sus cuartos al templo sin salir de palacio, Isabel ordenó que se construyesen pasadizos menos estables, con técnicas que debemos presumir de carpintería y albañilería menor, para permitirle el paso. Así lo hizo

${ }^{1}$ Este artículo forma parte de los resultados obtenidos gracias al proyecto I+D+i, HAR2015-65166-P (MINECO/FEDER) "Femenino singular: La mujer y las artes en la corte española en la Edad Moderna (reinas, nobles, artistas y empresarias)". Asimismo, su elaboración ha sido posible gracias a una Ayuda de Formación del Profesorado Universitario del Ministerio de Educación, Cultura y Deporte con la que realicé mi tesis doctoral titulada "Patronazgo y políticas artísticas en la corte de Carlos V: Francisco de los Cobos y Molina" y a una beca de alojamiento durante doce meses (a partir de diciembre de 2016) en la Residencia de Estudiantes de Madrid financiada por el Ministerio de Economía y Competitividad.

2 Fernando Chueca Goitia, Casas reales en monasterios y conventos españoles, Madrid, Xarait, 1982. Estos establecimientos les proporcionaron una infraestructura suficiente para el aposentamiento de su corte durante sus traslados Rafael DomíNGUEZ CASAs, Arte y Etiqueta de los Reyes Católicos. Artistas, residencias, jardines y bosques, Madrid, Alpuerto, 1993, pp. $233-234$. Sobre los problemas de aposentamiento de la corte del emperador Carlos V y su esposa Isabel véase María José REDONDO CANTERA, "La arquitectura de Carlos V y la intervención de Isabel de Portugal: palacios y fortalezas", en Ma J. REDONDO CANTERA y M. Á. Zalama, (coords.), Carlos $V$ y las artes: Promoción artística y familia imperial, Valladolid, Junta de Castilla y León/Universidad de Valladolid, 2000, pp. 67-106 y "La itinerancia de la emperatriz Isabel de Portugal y su recámara", en M. Cabañas Bravo, A. López-Yarto Elizalde y W. Rincón García, (coords.), El arte y el viaje, Madrid, CSIC, 2011, pp. $483-498$.

3 La construcción de estos aposentos regios comenzó en julio de 1492 dilatándose durante cuatro años. Consistían en una serie de salas, cámaras y cuadras muy amplias. En una de ellas se abrió en 1495 un balcón para que los monarcas asistieran a la misa. Para una reconstrucción del cuarto real, véase Felipe PEREDA Espeso, "Mencía de Mendoza (†1500), Mujer del I Condestable de Castilla", en B. Alonso (ed.), Patronos y coleccionistas: Los condestables de Castilla y el arte (siglos XV-XVII), Valladolid, Universidad de Valladolid, 2004, pp. 34-35. En la ciudad pinciana, aunque alejado del casco urbano, la reina ordenó construir un cuarto real en el monasterio jerónimo de Nuestra Señora del Prado a finales del siglo XV: Jesús URREA FERNÁNDEZ, "El Palacio Real de Valladolid", Boletín del Seminario de Estudios de Arte y Arqueología, no 40 (1975), pp. 241-242.

4 Sin embargo, la reina no llegó a ver terminado el proyecto. Véase el plano de Nicolás de Vergara el Mozo de 1594 por el que se documenta el cuarto real sobre la sacristía en Fernando MARÍAs, "L'ospedale del Cardinale Tavera a Toledo: da Hospitium Pauperum a Domus Infirmorum", Storia dell'arte, n 32, (1987), pp. 27-44 y "La arquitectura de Isabel la Católica en Toledo: casas temporales y moradas eternas", Ysabel, la Reina Católica. Una mirada desde la catedral primada, Toledo, Arzobispado de Toledo, 2005, pp. 126-127. Sobre la significación del monumento regio, su uso funerario y autocelebrativo, así como la construcción y configuración del cuarto real, véase: Rafael DomínguEZ CASAS, "San Juan de los Reyes: espacio funerario y aposento regio", Boletín del Seminario de Arte y Arqueología, no 56 (1990), pp. 375-379.

5 Miguel Ángel CAstillo OreJa, "Ideas, composición y diseño: antecedentes programáticos y precedentes tipológicos tradicionales de El Escorial”, en F. J. Campos y Fernández De Sevilla (coord.), El Monasterio de El Escorial y la Arquitectura (San Lorenzo de El Escorial, 8-11 de noviembre de 2002), Madrid, Instituto Escurialense de Investigaciones Históricas y Artísticas, 2002, pp. 2327. La vinculación regia con los centros de la orden jerónima se estrechó años después con el retiro a Yuste del emperador Carlos V decidido en 1554. Los datos sobre la construcción del palacio en Juan José MARTín González, "El Palacio de Carlos V en Yuste", Archivo Español de Arte, vol. 23, n 89, 1950, pp. 27-51. Sobre el proceso de elección, debate y materialización del retiro del emperador, véase: Jesús SÁENZ DE MiERA, “«Ecce elongavi fugiens, et mansi in solitudine». El retiro del emperador”, Carolus, Fernando Checa Cremades (comis.), Toledo, Sociedad Estatal para la Conmemoración de los Centenarios de Felipe II y Carlos V (Catálogo de la exposición celebrada desde el 6 de octubre de 2000 al 12 de enero de 2001), 2001, pp. 157-171.

6 A pesar de que la reina prefería asistir a misa en su oratorio privado, su palacio real también contaba con una galería que comunicaba las casas reales con la iglesia de San Antolín: Miguel Ángel ZaLAMA, Vida cotidiana y arte en el palacio de Juana I en Tordesillas, Valladolid, Universidad de Valladolid, 2003, pp. 144, 145 y 152. 
durante su estancia en el palacio de los Laso de Castilla, junto a la iglesia de San Andrés de Madrid, entre el verano de 1529 y el otoño de $1530^{7}$. De este modo, la emperatriz Isabel guardó siempre un gran cuidado por asegurarse el patronato y mantener su presencia en las iglesias anejas a sus cuartos reales, a veces incluso de manera simbólica como continuación y memoria de la labor protectora de las reinas castellanas que le precedieron como en el caso del monasterio de Santa María la Real de Nieva en Segovia. En 1538, movida por la devoción que su hija María y ella misma profesaban a la Virgen de la Soterraña, la emperatriz obtuvo una real cédula de Carlos V para la reforma de los aposentos regios en este cenobio dominicano fundado por la reina Catalina de Lancaster (1373-1418) en 1395 y protegido por su nuera María de Aragón (1403-1445) ${ }^{8}$. Con estas obras, Isabel de Avis recordaba la promoción arquitectónica y la presencia de los monarcas en el monasterio, que ya contaba con una tribuna regia. En 1540, ya fallecida la emperatriz, se contrataban también las obras de las tribunas del Alcázar de Madrid, las primeras en un edificio de la dinastía Habsburgo ${ }^{9}$. Por su parte, la infanta Juana, hermana menor de doña María, princesa de Portugal y gobernadora regente en España entre 1554 y 1559, también se aseguró el acceso desde su cuarto real a la iglesia del monasterio de las Descalzas Reales de Madrid, fundado por ella misma en las antiguas casas del tesorero Alonso Gutiérrez a partir de $1554^{10}$.

De este modo, la voluntaria cohabitación con el estamento religioso, constatable desde la Alta Edad Media en un modo bastante generalizado, constituyó un privilegio de exclusividad regia hasta su extensión al resto de la aristocracia durante el siglo XVI ${ }^{11}$. Es en este siglo cuando la paulatina imitación de los usos de la monarquía por parte de la nobleza se amplió al ejercicio del patronato religioso tanto en las instituciones de sus cada vez más extensos señoríos territoriales como en las enclavadas en sus áreas de influencia dentro de las ciudades de mayor envergadura ${ }^{12}$. Las clases medias y altas mantuvieron una necesaria relación con la preservación del honor y el prestigio social, estrategia necesaria de diferenciación con el resto de la sociedad

\footnotetext{
7 María José Redondo CAntera, "Palacios para una emperatriz itinerante. Usos residenciales de Isabel de Portugal (15261539)", en C. Martínez López y F. Serrano Estrella (eds.), Matronazgo y arquitectura: De la Antigüedad a la Edad Moderna, Granada, Universidad de Granada, 2016, pp. 281 y 291-292.

8 Diana Lucía Gómez-Chacón, El Monasterio de Santa María la Real de Nieva: Reinas y Predicadores en tiempos de reforma (1392-1445), Segovia, Diputación de Segovia, 2016, pp. 82 y 83.

9 Luis Cervera VerA, "Carlos V mejora el alcázar madrileño en 1540”, Revista de la Biblioteca, Archivo y Museo del Ayuntamiento de Madrid, no 5 (1979), p. 76 y “Obras en el Alcázar madrileño de Carlos V”, en F. Checa Cremades (dir.), El Real Alcázar de Madrid, Madrid, Nerea, 1994, p. 51; Veronique Gerard, De castillo a palacio. El Alcázar de Madrid en el siglo XVI, Bilbao, Xarait Ediciones, 1984, p. 72 y Begoña Alonso RuIz, "El Alcázar de Madrid. Del castillo trastámara al palacio de los Austrias (ss. XV-1543)", Archivo Español de Arte, vol. 87, n 348 (2014), pp. 347.

${ }^{10}$ María Ángeles Toajas Roger, "Memoria de un palacio madrileño del siglo XVI: las Descalzas Reales", Reales Sitios, 142, (1999), pp. 18-33; “Arquitectura en Madrid, 1560: las obras de Juana de Austria y la manera italiana”, en S. Diéguez Patao (ed.), Los lugares del arte: Identidad y representación, 1, Barcelona, Laertes, 2015, p. 53 y "Palacios ocultos: las Descalzas Reales de Madrid", en B. García García (ed.), Felix Austria. Lazos familiares, cultura política y mecenazgo artístico entre las cortes de los Habsburgo, Madrid, Fundación Carlos de Amberes, 2016, pp. 359 y ss. Véase también Magdalena SÁNCHEZ, "Where Palace and Convent Met: The Descalzas Reales in Madrid”, Sixteenth Century Journal: The Journal of Early Modern Studies, vol. 46 (2015), pp. 53-82.

${ }_{11}$ El proceso de extensión de esos derechos regios no estuvo exento de problemáticas, especialmente en lo referente a la autonomía e intimidad de las comunidades monásticas. A este respecto es importante señalar cómo en algunos casos excepcionales se produjo una cesión de la monarquía a la nobleza, cuyos ejemplos constituyen informaciones muy valiosas sobre la extensión del privilegio de aposentamiento en espacios de las comunidades religiosas y el rechazo de sus miembros a la presencia de personajes laicos en sus recintos. Para ilustrar los problemas de convivencia causados por el interés de ciertos próceres por acceder a los espacios monacales puede servir de ejemplo la solicitud del vallisoletano monasterio del Abrojo a Carlos V en 1531 para que impidiese la presencia de don Bernardino Pimentel, futuro marqués de Távara, y su mujer, Constanza de Bazán Osorio, en el cuarto real adosado al monasterio. Los religiosos franciscanos lamentaron que don Bernardino había abierto una ventana "que sale al cuerpo de la iglesia y sojudga todo aquel", añadiendo que la dicha ventana se había creado por hacer merced a la reina Isabel la Católica y solo podía ser abierta en caso de visita de la familia real desde donde tenían el privilegio de oír los oficios divinos. La queja finaliza con el relato de los inconvenientes provocados por el mal uso que hacía el duque de los espacios regios: traslación del Santísimo Sacramento desde el coro de la iglesia a una capilla del claustro y desasosiego de los religiosos porque no podían evitar ser vistos. Los monjes terminaron su petición suplicando que se cerrase dicha ventana y se otorgase el privilegio de residencia a una familia llana: "Peticiones de particulares", Archivo General de Simancas (en adelante AGS), Estado, Legajo 22, fol. 6r.

12 Ana Aranda Bernal, "El trabajo de las mujeres en la promoción de obras de arte y arquitectura durante la Baja Edad Media", en Ma E. DíEz Jorge, Arquitectura y mujeres en la historia, Madrid, Síntesis, 2015, p. 151.
} 
$\mathrm{y}$, consecuentemente, buscaron el contacto premeditado con las comunidades religiosas ${ }^{13}$. Asimismo, siempre con la vista puesta en el alcance de la salvación eterna, la oportunidad de asistir diariamente a la cotidianidad de la militancia religiosa proporcionaba al seglar la ocasión de saciar su interés por los ejemplos más cercanos a la beatitud y santidad, sujetos ejemplares de comportamiento a imitar. Finalmente, la instauración de capellanías y memorias más allá de la muerte coadyuvó a afrontar la verdadera cuestión para la que todo cristiano enriquecido se preparaba: la salvación del alma y la supervivencia del nombre en la tierra ${ }^{14}$.

Las damas de las distintas casas nobiliarias asumieron como parte de su condición aristocrática la gestión de estas iniciativas pías que dotaban de prestigio al linaje. Por otro lado, en determinadas circunstancias como la viudedad o en los casos en los que se convirtieron en receptoras de herencias testamentarias, hubieron de asumir dentro de su actividad algunas decisiones con consecuencias sobre el manejo del patrimonio dinástico. Para comprender la labor de estas damas es especialmente interesante ahondar en los lazos de parentesco que las unieron ${ }^{15}$, materno-filial en el que caso que presentamos a continuación, imbricados estrechamente con su consciencia de pertenencia a un linaje a cuyo mantenimiento estuvieron obligadas. No obstante, es posible atisbar algunas estrategias de preservación de la autonomía a tenor de sus actuaciones, fundamentalmente en el apartado de las fundaciones religiosas y funerarias ${ }^{16}$.

Los acuerdos a los que llegaron con los conventos, monasterios e iglesias que pusieron bajo su protección incluyeron estos derechos de disfrute en exclusiva de asistencia a la vida de la comunidad. Las cláusulas reconocían diversas regalías, aunque aquí nos centraremos en la anexión de dependencias privadas de seglares a los conjuntos monacales, así como en el punto de encuentro entre ambas a través de elementos privilegiados de observación en la iglesia, las tan extendidas tribunas a las que se accedía mediante pasadizos, estructuras heredadas de la tradición andalusí que se mantuvieron durante toda la Edad Moderna ${ }^{17}$. Estos elementos ocasionaron muchos problemas de convivencia entre las corporaciones religiosas y los patronos, además de tener sus lógicas repercusiones en la disposición arquitectónica de todo el conjunto. El hecho de que el Concilio de Trento debatiese sobre las dificultades de compatibilidad entre la actividad propia de los religiosos y religiosas, que sintieron su privacidad invadida, e intentase aliviar las presiones de un poderoso grupo seglar por asomarse desde la ventana indiscreta, incluso "vivir la experiencia religiosa" ${ }^{18}$, nos permite imaginar la dimensión y extensión de estos inconvenientes.

La variabilidad de casos de convivencia fue muy variada. Así lo demuestra que incluso algunos notables acogieron en sus moradas personajes de especial relevancia como fue el caso de la beata Mari Díaz quien vivió en Ávila a mediados del siglo XVI en las casas de Guiomar de Ulloa. Allí su fama piadosa transcendió los muros de las casas principales de doña Guiomar donde fue visitada, entre otros, por Pedro de Alcántara y Teresa de Jesús. Finalmente, en torno a 1564 ó 1565 consiguió el permiso de Álvaro de Mendoza, obispo de Ávila, para trasladarse a un pequeño aposento con tribuna frente al altar mayor de la iglesia de San Millán donde vivió hasta su muerte en $1572^{19}$. En otras ocasiones, estas damas acogían una

\footnotetext{
13 Un amplio análisis de las funciones que desempeñaban estas funciones para la nobleza hispánica en Ángela ATIENZA, Tiempos de conventos: Una historia social de las fundaciones en la España moderna, Madrid, Marcial Pons, 2008, pp. 151-326.

14 Fernando Martínez GiL, Muerte y sociedad en la España de los Austrias, Cuenca, Universidad de Castilla-La Mancha, 2000, p. 215.

15 Esther Alegre Carvajal, "Introducción”, en E. Alegre Carvajal (dir.), Damas de la Casa de Mendoza: Historias, leyendas y olvidos, Madrid, Polifemo, 2014, pp. 21-22 y 34-35.

16 Felipe PeredA, "Liturgy as Women's Language: Two Noble Patrons Prepare for the End in Fifteenth-Century Spain", en T. Martin (ed.), Reassessing the Role of Women as 'Makers' in Medieval Art and Architecture, Leiden/Boston, Brill, 2012 , pp. 937-988.

17 Cristina DE Mora Lorenzo, "El pasadizo en el Madrid de los Austrias (siglo XVII). Pervivencia de elementos arquitectónicos encubiertos de tradición medieval", Madrid. Revista de arte, geografía e historia, no 6 (2004), p. 261.

18 Felipe Serrano Estrella, "Nuevos modelos arquitectónicos para la clausura femenina de la Contrarreforma", en M. E. Díez Jorge, Arquitectura y mujeres en la historia, Madrid, Síntesis, 2015, pp. 273-304.

19 Jodi BiLinkoff, The Avila of Saint Teresa: Religious Reform in a Sixteenth-Century City, Ithaca, Cornwell University Press, 2014, pp. 99-100.
} 
comunidad monástica en el complejo que conformaban sus residencias, de manera circunstancial o con el objetivo de fundar un nuevo convento. En las siguientes líneas pondremos el foco en los casos de la hermana del obispo de Ávila y de su hija para comprender mejor este fenómeno.

\section{El seglar se asoma al espacio sagrado, el religioso sacraliza el palacio: María de Mendoza y Santa Teresa de Jesús}

María de Mendoza y Sarmiento (1508-1587), VII condesa de Ribadavia entre 1582 y $1584^{20}$, además de señora de Sabiote, Torres, Canena y Recena; nació en Valladolid fruto del matrimonio entre Juan Hurtado de Mendoza, Adelantado de Galicia, y María Sarmiento, II condesa de Ribadavia ${ }^{21}$. En el otoño de 1522, a la edad de catorce años, casó en la ciudad pinciana con el secretario imperial Francisco de los Cobos y Molina (ca. 1477-1547) con el que tuvo dos hijos: Diego de los Cobos (1523-1576) I marqués de Camarasa desde 1543 tras su boda con Francisca Luisa de Luna ( $\uparrow 1585)^{22}$ y María Sarmiento, duquesa de Sessa (15261604) por su matrimonio con Gonzalo Fernández de Córdoba (1524-1578) concertado en $1538^{23}$.

La privanza de Cobos con Carlos V le había permitido gozar de privilegios exclusivos también sobre el uso de espacios regios en recintos monacales. Su cercanía con el monarca había sido clave de su éxito y Cobos aprovechó también la oportunidad de disfrutar de ciertas prerrogativas. Al final de su vida tenemos testimonios de su predilección por el retiro a los cuartos reales de los monasterios de San Jerónimo en Madrid $^{24} \mathrm{y}$, de nuevo, al monasterio del Abrojo ${ }^{25} \mathrm{Al}$ parecer, la relación con esta última institución se mantuvo por parte de ambos miembros del matrimonio porque María de Mendoza firmó allí un testamento en $1563^{26}$.

La historia de la promoción edilicia de Francisco de los Cobos y María de Mendoza tiene como escenarios principales Úbeda y Valladolid, sus respectivas ciudades natales. La ciudad del Pisuerga se convirtió en una apuesta por establecer una residencia representativa en la corte, exitosa por cuanto la familia imperial pasó largas temporadas morando su palacio de la Corredera de San Pablo ${ }^{27}$. María de Mendoza residió la mayor parte de su vida en Valladolid donde, a partir de 1524, su marido y ella levantaron sus casas principales bajo la dirección arquitectónica de Luis de Vega ${ }^{28}$ (fig. 1) en un solar ubicado

20 Gonzalo Francisco Fernández SuÁrez, Os condes de Ribadavia durante o reinado de Felipe II, La Coruña, Toxosoutos, 2003, pp. 22-26.

21 Archivo de la Casa Ducal de Medinaceli (en adelante ADM), Archivo Camarasa, Sección Indiferente, Legajo 33, s/f.

22 "Capitulaciones matrimoniales entre Diego de los Cobos y Francisca Luisa de Luna", ADM, Archivo Camarasa, Sección Camarasa, Legajo $4, \mathrm{n}^{\circ}$ 6d.

23 Hayward Keniston, Francisco de los Cobos, secretario de Carlos V, Madrid, Castalia, 1980, pp. 209 y 252.

24 "Carta de Francisco de los Cobos al emperador Carlos V", AGS, Estado, Legajo 73, fol. 175 y Manuel FERnÁNDEZ ÁlvaREZ, Corpus documental de Carlos V, II, Salamanca, Universidad de Salamanca, 1981, p. 444.

25 Como en el caso de Bernardino Pimentel, en la Semana Santa de 1545 los monjes franciscanos escribieron al príncipe Felipe para recordarle la facultad exclusiva otorgada a la familia real de abrir ciertas puertas y ventanas (véase nota 10). Añadían también en la misiva al aún heredero de la Corona que habían sido informados por Hernando Bernaldo, criado de Cobos, que su señor mantenía la intención de abrirlas. Así pues, advertían a Felipe que si este acto llegara a consumarse crearía un peligroso precedente porque en lo sucesivo cualquier gran señor del reino podría seguir el mismo camino. Finalizaban su misiva, como en el caso anterior, pidiendo al monarca que prohibiese a Cobos la apertura de tales puertas o ventanas: KenISTON, 1980, pp. 266 y 267.

26 Ibidem, p. 309 y Sergio Ramiro Ramírez, "La herencia de doña María de Mendoza, VII condesa de Ribadavia, y la dispersión de la colección familiar de su palacio en Valladolid“, Erasmo: Revista de historia bajomedieval y moderna, nº 5 (2018), p. 46.

27 Javier PÉrez GIL, El palacio real de Valladolid: sede de la corte de Felipe III, Valladolid, Universidad de Valladolid, Secretariado de Publicaciones e Intercambio Editorial, 2003, pp. 53 y ss.; Sergio RAmiro RAMírEz, "Bienes muebles y ambientes del palacio de Francisco de los Cobos en Valladolid”, en S. Diéguez Patao (ed.), Los Lugares del Arte: Identidad y representación, I, Barcelona, Laertes, 2014, pp. 159-174.

28 URREA FernÁNDEZ, 1975, pp. 241-258 y “El arquitecto Luis de Vega (h. 1495-1562), en A introduçao da arte da Renascença na Península Ibérica, Coimbra, Universidad de Coimbra, 1981, pp. 150 y 151; REDONDo CANTERA, 2000, pp. 89-93 y “El palacio 


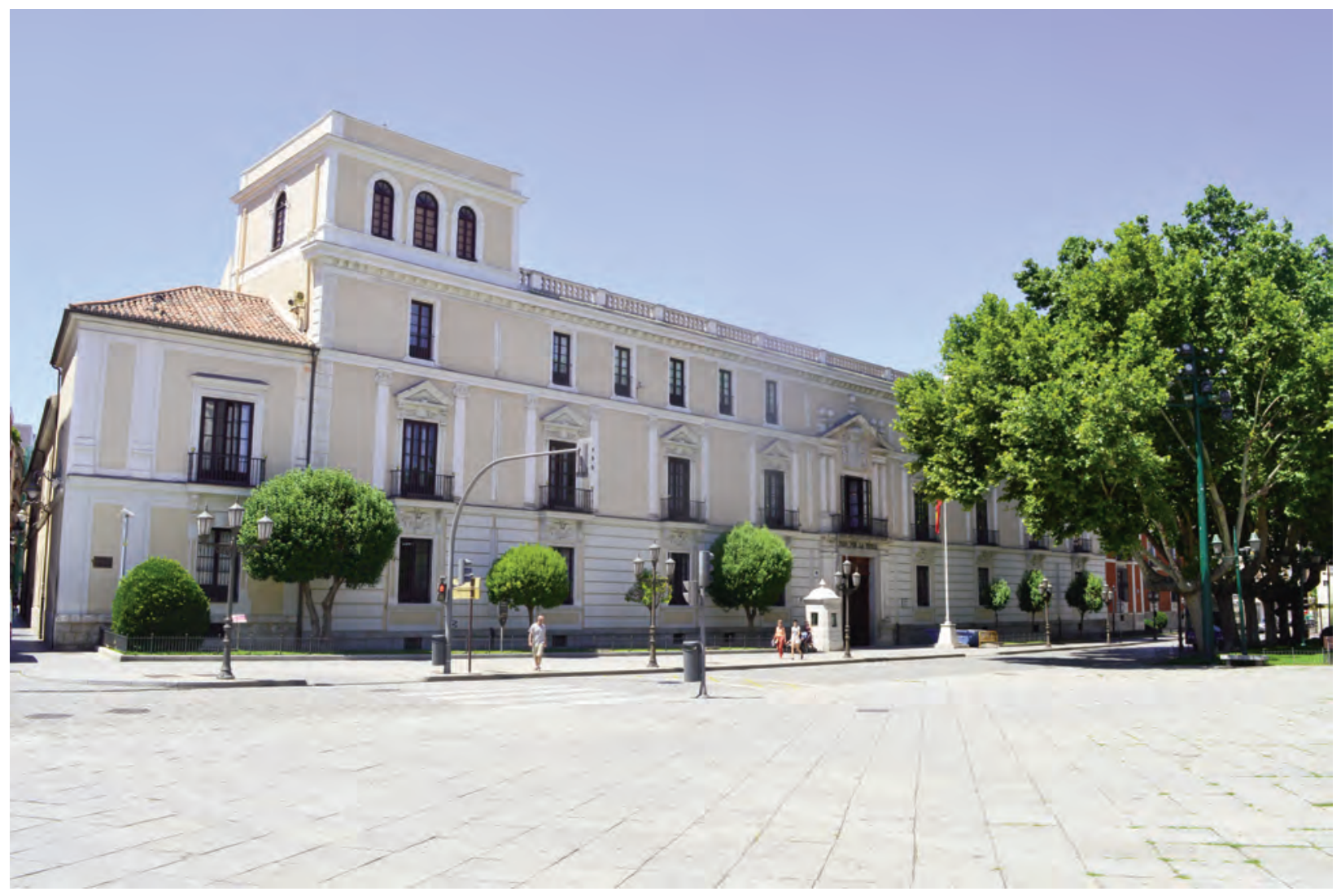

Fig. 1. Vista de la fachada actual del antiguo palacio de Francisco de los Cobos y María de Mendoza, ahora Capitanía General del Ejército de Tierra, a partir de 1524, Valladolid.

frente al monasterio dominico de San Pablo que sus padres habían cedido al matrimonio como parte del pago de la dote 29 .

Desde la primera fase de su construcción, el palacio abrazó arquitectónicamente la desaparecida iglesia de Nuestra Señora del Rosario, perteneciente a la cofradía y hospital del mismo nombre, situada en el costado sur de la residencia ${ }^{30}$. Su planta de nave única y estrecha, un tanto irregular, tenía una cabecera cuadrangular como es posible reconstruir gracias a los planos levantados en el siglo XIX antes de su demolición donde aparece tras la escalera imperial construida en el siglo XVIII por Ventura Rodríguez ${ }^{31}$ (fig. 2). En la cuarta década del siglo XVI, el matrimonio Cobos-Mendoza ya había conseguido abrir un "paso y callejón" que comunicase su palacio con el templo a través de un patio porticado emplazado tras el prin-

'imperial' de Francisco de los Cobos en Valladolid”, en M. C. Improta (ed.), El San Juanito de Úbeda restituido, Florencia, Edifir, 2014, pp. 229-247; PÉREZ GIL, 2003.

${ }^{29}$ Los documentos sobre las capitulaciones matrimoniales y el testimonio del velatorio de los novios en ADM, Archivo Camarasa, Sección Ribadavia, Legajo 4, número 28; Legajo 5, número 32 y Legajo 5 s/f. Los documentos ya fueron citados en Keniston, 1980, pp. 73 y ss.

30 Keniston, 1980, p. 94.

31 En el Archivo de la Casa Ducal de Medinaceli se conservan tres planos del siglo XVIII que representan el emplazamiento original de la escalera del siglo XVI, en concreto, es posible distinguirla en dos planos firmados por Matías Machuca en 1730 de las dos plantas superiores del palacio: ADM, Mapas y planos, Cajón V, reproducidos en Antonio SÁNCHEZ GonZÁLEZ, El arte de la representación del espacio, mapas y planos de la colección Medinaceli, Huelva, Universidad de Huelva, 2017, pp. 454-457. 


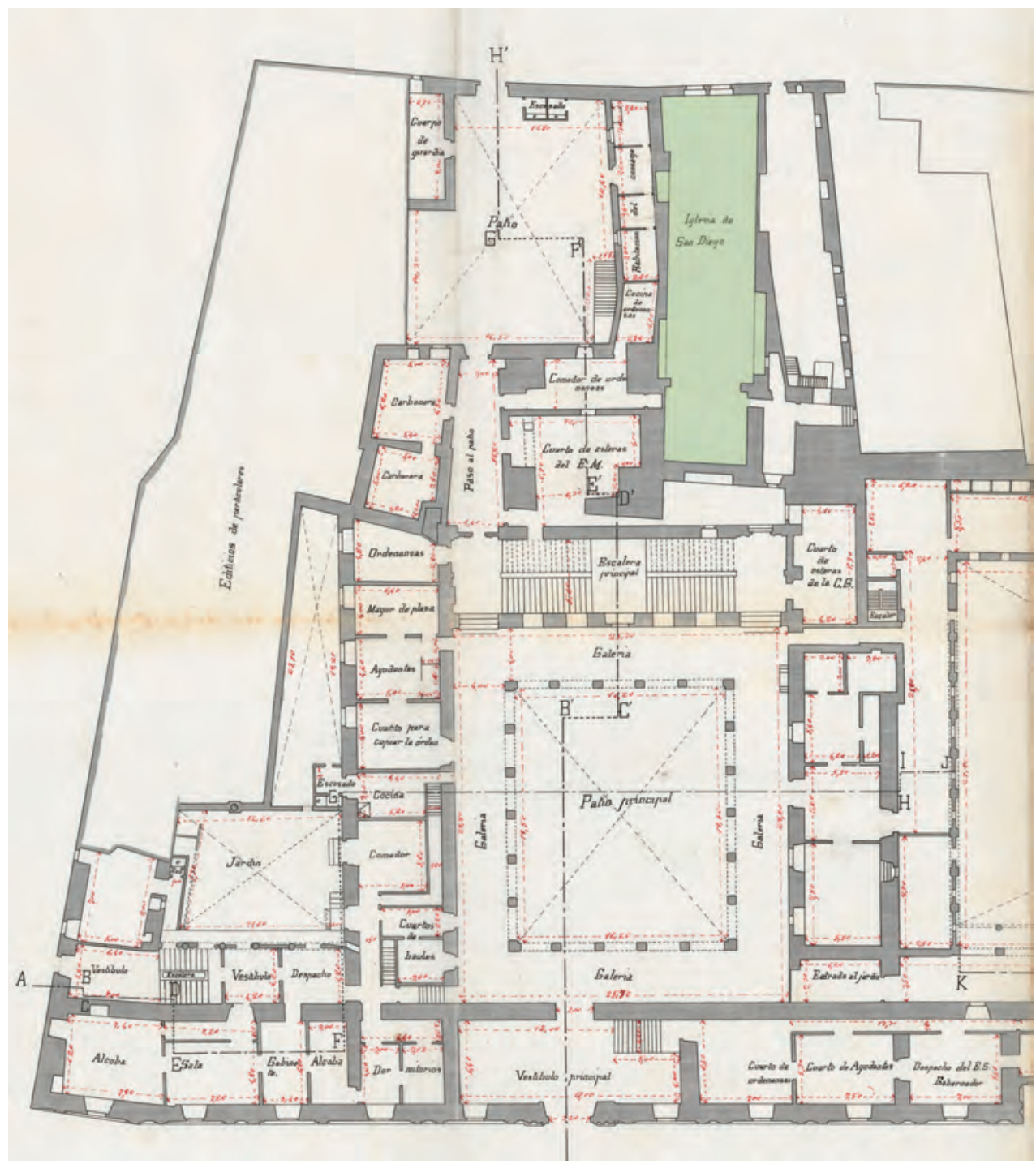

Fig. 2. Plano de la planta baja y entresuelo de la Capitanía General de Valladolid [Detalle], 1887, Madrid, Archivo General Militar, AFI-96-07.

cipal, al que se accedía mediante una puerta situada en la crujía meridional de este último, como puso de relieve Redondo Cantera sirviéndose de un plano de Ventura Rodríguez realizado en $1762^{32}$ (Fig. 3). Por otro lado, en la escalera principal se habilitaron unas gradas y una puerta de piedra que enlazaban su mesa con la capilla gracias a un paso conformado por dos paredes en escuadra ${ }^{33}$.

Los cofrades compensaban así las donaciones del matrimonio que habían financiado unas obras en la iglesia y dotado al templo de ciertas telas y orfebrería litúrgicas ${ }^{34}$. Esta vinculación se estrechará durante

32 Redondo Cantera, 2000, p. 96.

33 PÉreZ GIL, 2003, p. 308.

34 Juan Agapito Revilla, "La Capilla Real de Valladolid”, Boletín de la Sociedad Española de Excursiones, vol. XLVIII (1944), pp. 167-173 y REDONDO CANTERA, 2000, p. 92. 


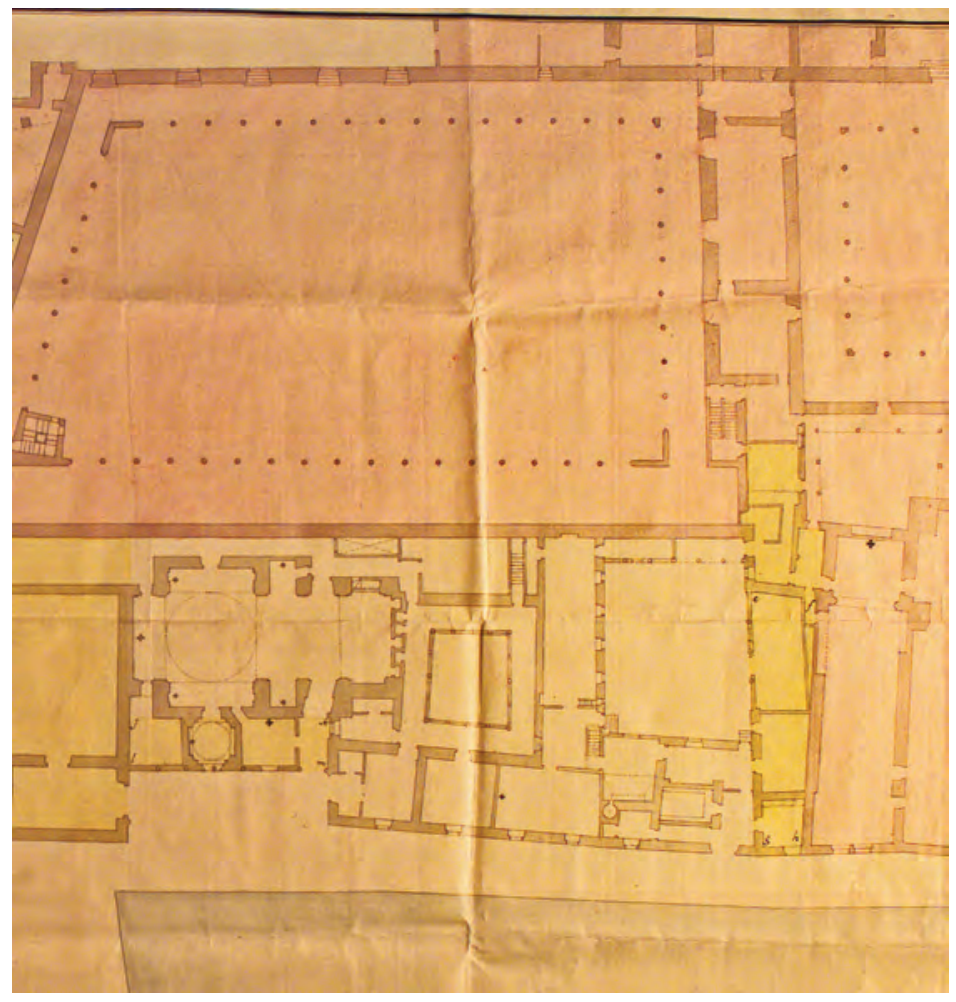

Fig. 3. Ventura Rodríguez, Plano del Convento de San Diego de Valladolid, [Detalle], 1762, Madrid, Archivo General de Palacio, Planos, Mapas y dibujos, P5916. las estancias de la emperatriz Isabel de Portugal, especialmente en la última y más larga que se extiende desde verano de 1536 hasta septiembre de 1538 , cuando favoreció la iglesia con la donación de orfebrería y el encargo de un retablo. Isabel de Portugal mandó edificar también una tribuna de trece pies de ancho (casi cuatro metros) y unos veinticuatro pies de largo (poco más de siete metros) con su correspondiente balcón hacia el templo. La soberana consideró siempre la iglesia de su propiedad y, en su última salida de palacio en 1538, dejó expresamente ordenado en una carta a sus cofrades y capellanes que no se modificase en nada el acceso hasta que ella misma volviese a utilizarlo ${ }^{35}$.

El fallecimiento de la emperatriz al año siguiente dejó a su hijo Felipe como heredero de su privilegio. El sucesor al trono moró en palacio durante sus estancias en la ciudad y disfrutó del acceso a la iglesia, al igual que sus padres, hasta la muerte de su primera mujer María Manuela de Portugal en $1545^{36}$, cuando el príncipe abandonó su uso en favor de otras residencias en la ciudad ${ }^{37}$. Bajo estas nuevas circunstancias, María de Mendoza recuperó su labor de patronato sobre el hospital e iglesia y en 1552 obtuvo licencia para usar la tribuna real, puesto que además de haber costeado numerosos ornamentos y obras en el templo en vida de Cobos, ahora se comprometía a sufragar unas intervenciones en la ruinosa estructura hospitalaria para las que mandaría traer de nuevo al ya Maestro Mayor de Obras Reales Luis de Vega ${ }^{38}$.

Por su parte, Úbeda se convirtió para la familia en la ciudad simbólica ligada a la idea del origen y solar del linaje, así como destino de los mayores esfuerzos del mayorazgo instituido en su primogénito Diego, puesto que se acompañaba de las posesiones señoriales y títulos en el Reino de Jaén, además del patronato sobre los panteones familiares ${ }^{39}$. Las primeras decisiones del matrimonio en la ciudad fueron probable-

35 Agapito Revilla, 1944, pp. 173 y 174.

36 Agapito Revilla, 1944, pp. 164-167.

37 Javier PÉrez GIL, "La imagen de la corte en Valladolid: Palacio Real y Palacio de los condes de Benavente", en D. Villalobos Alonso y S. Pérez Barrero (eds.), Arquitectura palaciega en el Valladolid de la Corte, Valladolid, Universidad de Valladolid, 2012, pp. 44 y 45. Incluso proyectó la construcción de uno nuevo: Juan AGAPITO Y REVILLA, "Un proyectado palacio real en Valladolid en el siglo XVI", Boletín de la Academia de Bellas Arte de Valladolid, no 6 (1932), pp. 324-331.

38 Agapito y Revilla, 1944, pp. 167-173. Para conocer más sobre a labor de Luis de Vega como Maestro Mayor de Obras Reales véase Eva Guerrero DE Llanos, "El uso de la Arquitectura como reafirmación política: la Maestría Mayor de Obras Reales en el siglo XVI y Luis de Vega”, en S. Diéguez Patao, (ed.), Los lugares del arte: Identidad y representación, vol. I, Barcelona, Laertes, 2015, pp. 133-158.

39 Claudio TESSARI, "Autocelebración y Arquitectura. La familia Cobos y Molina y Andrés de Vandelvira en Úbeda", Periferia, (1991), pp. 159-176; Javier PÉrez GIL, "El palacio de Francisco de los Cobos en Úbeda y la notoriedad del linaje", Mágina, $\mathrm{n}^{\circ} 10$ (2002), pp. 159-174 y "El valor del retrato. Francisco de los Cobos y la notoriedad del linaje", en J. García Nistal, Imagen y documento: materiales para conocer y construir una historia cultural, León, El Forastero, 2014, pp. 61-87 y Sergio 
mente fruto de la iniciativa de Cobos, aunque doña María siempre supervisó la administración de los proyectos por las ocupaciones políticas de su marido ${ }^{409}$. En la primavera de 1525 dieron la orden para la construcción de la Capilla de la Purísima Concepción en la parroquia de Santo Tomás preparando ya su futuro sepelio junto a los padres de su marido. El proyecto contaba con coro propio y tribuna en uno de sus laterales para la asistencia a los oficios divinos ${ }^{41}$. Sin embargo, su primera experiencia fundadora no fue satisfactoria pues la amplia dotación de capellanes y la gran cantidad de misas celebradas interferían con el ritmo habitual de la iglesia. Los patronos pronto notaron los inconvenientes que conllevaba compartir espacio religioso con otros titulares y nueve años después iniciaron la fundación de una iglesia de propiedad exclusiva junto a sus casas bajo la advocación del Salvador:

Y por que por parte del dicho Comendador Mayor se le dijo que su voluntad era que el culto divino se ensanchase y que la capellanía de la Concepción era tan agosta y estrecha en la qual no se podían bien celebrar los divinos oficios con la decencia y decoro que se requeria asi por la estrechez de la capilla como por el concurso de las horas que se decían por el rector y beneficiados de la dicha iglesia de Santo Thomas y por los capellanes de la dicha capilla que los unos a los otros se impedían al decoro de las horas $[\ldots]^{42}$.

Es interesante observar cómo los distintos miembros de la familia Cobos que habían aprovechado la influencia de don Francisco para hacer carrera en la corte, atravesaron por un proceso parecido a la hora de ordenar su sepultura. Sus exigencias eran superiores a las del resto de familias ubetenses y las dimensiones de sus fundaciones causaron problemas de espacio en las iglesias de la ciudad que finalmente se resolvieron con la erección de espacios propios donde ser enterrados. Tal es el caso del secretario Juan Vázquez de Molina y su hermano Diego de los Cobos, obispo de Jaén, hijos de su primo hermano Jorge de Molina. Ambos fundaron una capilla funeraria junto al testero del evangelio en la iglesia colegial de Santa María de los Reales Alcázares de Úbeda una capilla familiar que finalmente no se llevó a cabo por la excesiva estrechez del solar disponible ${ }^{43}$. Una carta de don Diego a su hermano, fechada en Úbeda a 26 de agosto de 1542, nos informa de que el problema estaba siendo tratado con los propietarios de las parcelas y edificios cercanos. Debía albergar esperanzas de su resolución pues afirma que en un plazo breve de tiempo pediría al arquitecto Luis de Vega trazar la nueva obra. Prosigue don Diego argumentando que no sería conveniente dejar el Sacramento en la capilla, ya que sufrirían intromisiones del resto religiosos de la colegiata, lo que significaría estar a merced -lo denomina "servidumbre"- de las necesidades litúrgicas de los capellanes sin poder tener el control de acceso.

porque a de ser señor de la capilla el cura y los sacristanes y no puede aver clausura, aviendo tantas llaves, y ser desasosiego para los capellanes que celebraren los oficios en la capilla, estando en ellos que entrasen y saliesen

RAMIRO RAMírez, "Francisco de los Cobos y la fama: promoción arquitectónica y literatura cortesana de oposición”, Anales de Historia del Arte, 23, (2013), pp. 71-88.

40 María de Mendoza lamentó durante su viudedad que Francisco de los Cobos no le permitió tomar decisiones ni opinar contra el parecer de su marido "por el acatamiento, respeto y miedo reverencial que le tenia, como por su gran poder, y a quien ella no osara resistir, como por otros grandes daños, e inconvenientes que a ella le podrían resultar de mostrar que quería contravenir su voluntad, y aun con todo esso por su gran poder no pudiera salir con ello": "Memorial del pleyto que don Diego de los Cobos y Luna, Marqués de Camarasa, [...] trataron en esta Real Audiencia contra los bienes que quedaron de don Diego Sarmiento, Conde que fue de Ribadavia, y Deán de la Santa Yglesia de Cordova, [...]", 1627, Biblioteca Nacional de España [BNE], Porcones, 61/49, f. 7 r.

41 Miguel RuIz Prieto, Historia de Úbeda, vol. II, Úbeda, Imprenta Gutenberg, 1906 [ed. Úbeda, Asociación Cultural “Alfredo Cazabán Laguna", 2006], pp. 89 y 90 y KENISTON, 1980, p. 87. La arquitectura de la capilla ha desaparecido junto a la iglesia en un proceso de ruina progresiva que se extiende desde, al menos, finales del siglo XVIII hasta el siglo XX.

42 "Documentos sobre la fundación de la Sacra Capilla de El Salvador", Archivo General de Andalucía (en adelante AGA), Documentos andaluces de la Casa Ducal de Medinaceli, Sabiote y otros señoríos de la casa de Camarasa en el Reino de Jaén 493/056-085, Microfilm 032-004 nº 1, fol. 2r.

43 Arsenio Moreno Mendoza, Úbeda renacentista, Madrid, Electa, 1993, pp. 89 y 90. 
por el sacramento, y a mi me parece que es servidumbre. Vuestra merced lo comunique y me avise, porque yo he dicho a estos señores de la iglesia, que dándonos el arco, tomaremos el sacramento en la capilla o les daremos otra do le pongan y dizen que holgaran ${ }^{44}$.

Este ejemplo evidencia la batalla por el control del espacio en el interior del templo entre los mantenedores de la iglesia y los financiadores del culto. Creo que la problemática derivada de la yuxtaposición de distintas capellanías y celebraciones en Santo Tomás, junto al caso de la capilla de la colegiata, constituyeron el germen de la decisión tomada por Francisco de los Cobos y María de Mendoza de trasladar su propio enterramiento a la Sacra Capilla de El Salvador (fig. 4), edificio singular que solo tenía como antecedente la Capilla Real de Granada ${ }^{45}$. La redacción de unos estatutos propios preparados por Francisco de los Cobos resolvió definitivamente cualquier tipo de colisión con los religiosos ${ }^{46}$.

La nueva iglesia-panteón se situó en una manzana que tanto Cobos como su mujer habían paulatinamente adquirido en su totalidad con el objetivo de construir un complejo dotado con una universidad y un hospital que se sumarían al reformado palacio familiar. Además de la cercanía física de la residencia, el matrimonio había proyectado unos aposentos junto a la iglesia. En una de las copias del contrato del año 1540 con Andrés de Vandelvira y Alonso Ruiz para retomar las obras del templo paralizadas un año antes, al tratar de las tribunas en la iglesia, una escritura al margen y de letra diferente recoge la última decisión de Cobos al respecto "que no se hiziesen ni los aposentos ni ventanajes más que las puertas y sacristía”. La resolución fue adoptada, según el documento, cuando regresó a su ciudad natal en 1547 para pasar sus últimos meses de vida y está claramente vinculada con el viaje, hasta ahora desconocido, que Luis de Vega realizó en este tiempo a Úbeda acompañando al Comendador Mayor $^{47}$.

44 "Carta de Diego de los Cobos a Juan Vázquez de Molina” AGS, Estado, Legajo 58, fols. 112 y ss. Finalmente, los hermanos acabarían desechando este proyecto en favor de edificaciones particulares. Juan Vázquez de Molina transformó su palacio frente a la colegiata de Santa María de los Reales Alcázares en el convento dominico de la Comunidad de Madre de Dios de las Cadenas reservándose también una vivienda con tribuna hacia la capilla: José Manuel ALMANSA MoRENO, "Las pinturas murales del palacio Vázquez de Molina de Úbeda", Boletín del Instituto de Estudios Giennenses, no 186 (2003), pp. 45-81 y RUIz PRIETO, 2006, pp. 177 y ss. Su hermano Diego fundó el Hospital de Santiago a las afueras de la ciudad donde mandó enterrarse en el presbiterio: Ibidem, pp. 207 y ss. Su testamento en AGS, Contaduría de Mercedes, 33, 36, fols. 1961 y ss.

45 El precedente simbólico e ideológico directo de El Salvador fue la Capilla Real de Granada, único edificio de su tiempo totalmente exento creado ex profeso para cumplir con una finalidad funeraria: Víctor NiETo AlCAIDE, "El Salvador de Úbeda y la imagen clásica de capilla funeraria", en A. Moreno Mendoza y J. M. Almansa Moreno, Úbeda en el siglo XVI, Úbeda, El Olivo, 2002, pp. 445-452 y TESSARI, 1991, p. 170. Asimismo, compartía con el templo granadino la misma condición estatuaria. En el interrogatorio de 1569 a petición de María de Mendoza, el testigo Luis de Biedma trazó el paralelismo entre ambas fundaciones "Paresce a este testigo que la a aprobado e confirmado e la tiene por de las cosas mas insines que en toda esta Andaluzia e dicen que es como la capilla real de Granada porque tiene los mismos estatutos": "Interrogatorio realizado a petición de María de Mendoza sobre su condición de patrona y fundadora de la Sacra Capilla de El Salvador", AGA, Documentos andaluces de la Casa Ducal de Medinaceli, Sabiote y otros señoríos de la casa de Camarasa en el Reino de Jaén 475/604-634, Documento microfilmado 013-027 n 1, s/f. De entre la abundante bibliografía que ha tratado distintos aspectos de la Sacra Capilla de El Salvador, destacamos: Caroline HorstmeIER, "Die Sacra Capilla de El Salvador in Úbeda (Andalusien): Eine Studie zur Memorialkunst und Sepulkralkultur der Neuzeit in Spanien”, Tesis doctoral, Berlín, Universidad de Berlín, 2011 y Fernando MARÍAS, "La Sacra Capilla de El Salvador de Úbeda: entre Italia y España", en IMPROTA, 2014, pp. 205-228.

46 "Estatutos hechos por Francisco de los Cobos, como patrón único de la iglesia del Salvador de Úbeda, para su buen régimen y gobierno", AGA, Documentos andaluces de la Casa Ducal de Medinaceli 479/220-280, Sabiote y otros señoríos de la casa de Camarasa en el Reino de Jaén, Microfilm 016-063, s/f.

47 En febrero de 1547, Luis de Vega marchó con Cobos a Úbeda, probablemente para disponer el futuro de las obras en El Salvador, así como del resto de los proyectos en sus posesiones del sur: "Minuta de carta de Felipe II a Antonio de Cárdenas, teniente de alcaide provisional de los Reales Alcázares de Sevilla”, AGS, Estado, Legajo 74, Documento 20. Agradezco a Candela Gaitán Salinas por revelarme esta información en el transcurso de un trabajo que preparamos sobre la figura de Luis de Vega. En septiembre de 1547 desde Monzón, el príncipe Felipe aceptó pagar su salario mientras estuvo ausente, como 


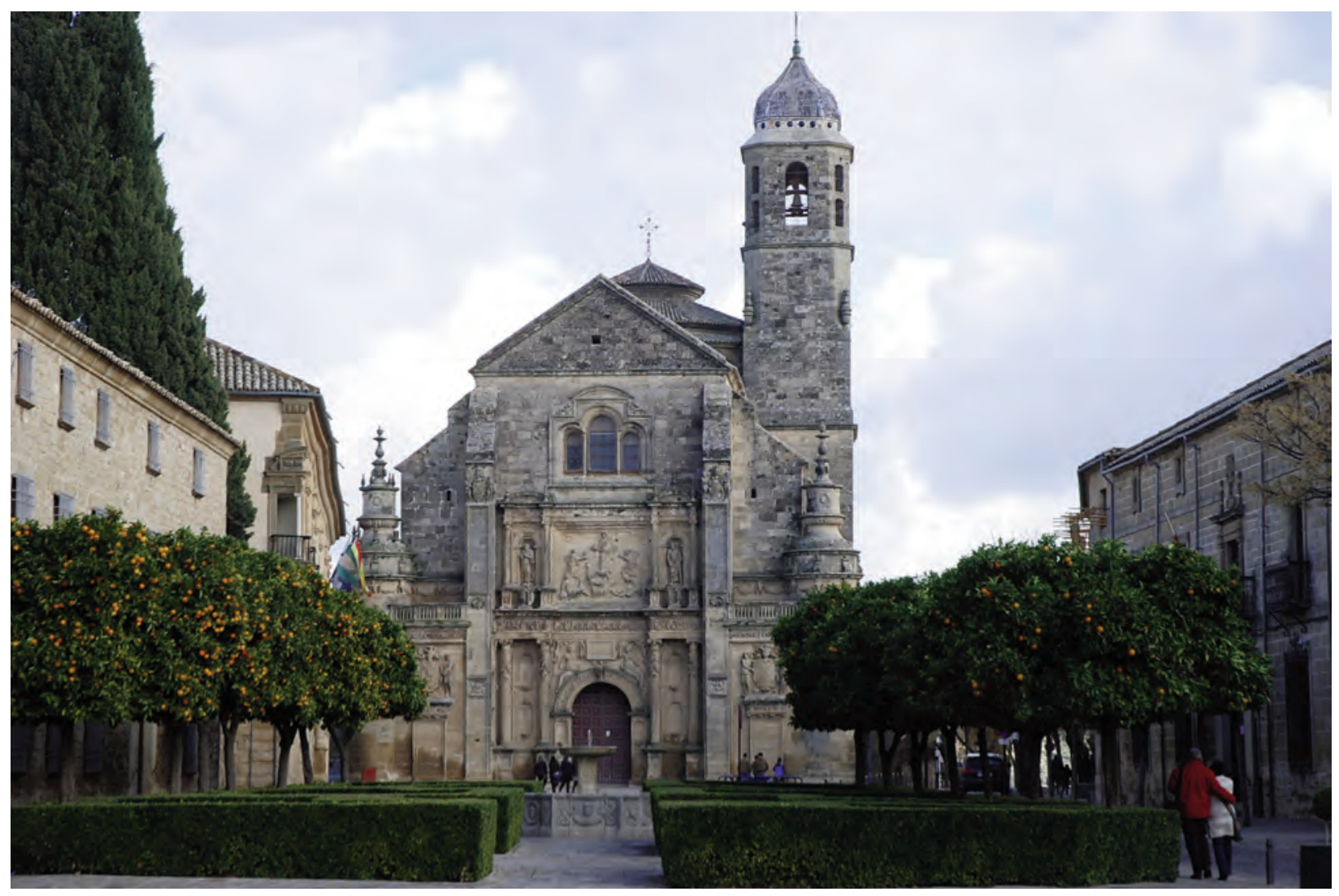

Fig. 4. Diego de Siloe y Andrés de Vandelvira, Sacra Capilla de El Salvador, 1536-1559, Úbeda (Jaén).

Tras la muerte de Cobos, las exposiciones públicas de doña María se redujeron sustancialmente, en gran parte debido a la necesidad de adaptarse a una imagen de la viuda ejemplar y a una estrategia para la defensa de su independencia como administradora de los cuantiosos bienes familiares de la que ella fue usufructuaria de por vida ${ }^{48}$. Mientras que su marido aún vivía, María de Mendoza participó de los eventos cortesanos en los que se mostró siempre con un gran esplendor acorde a su posición social y su fortuna ${ }^{49}$. Sin embargo, tras el 10 de mayo de 1547, doña María no volvió a compartir espacio en la iglesia con el resto de feligreses, tal y como sabemos que hizo, por ejemplo, en 1546 para escuchar un sermón en Santa María de la Almudena de Madrid $^{50}$. Por contra, la mayoría de las noticias sobre ella durante los cuarenta años en

si hubiera desarrollado su actividad en residencia en las obras reales: "Minuta de carta de Felipe II a Luis de Vega", AGS, Estado, Legajo 75, Documento 254.

48 Ramiro RAmírez, 2018, pp. 45-48. Véase también Ana ArAnda Bernal, "La participación de las mujeres en la promoción artística durante la Edad Moderna", Goya, no 301-302 (2004), p. 231 y "El trabajo de las mujeres en la promoción de obras de arte y arquitectura durante la Baja Edad Media”, en Díez Jorge, 2015, pp. 145-182. El poder que pudieron acumular las viudas nobles se limitó bruscamente a partir de la puesta en marcha de los preceptos contrarreformistas que reforzaron la supervisión personal de la iglesia y el estado sobre el estado civil de las mujeres nobles con el objetivo de controlar la acumulación de poder y limitar la posible dispersión del patrimonio dinástico en sus mandas testamentarias: ALEGRE Carvajal, 2014, p. 42.

49 Según el biógrafo de Francisco de Borja, María de Mendoza incluso reprochó en una ocasión a Leonor de Castro, esposa del posteriormente santo jesuita, la humildad de sus vestidos: Keniston, 1980, p. 242.

50 Marcel Bataillon, Erasmo y el erasmismo, Barcelona, Crítica, 1983, p. 236, nota 35. 
los que sobrevivió a Cobos están ligadas al evergetismo religioso ${ }^{51}$ pero, sobre todo, al recogimiento y encierro piadoso como preservación del honor ${ }^{52}$.

El matrimonio había tenido siempre una tendencia a la piedad intimista e introspectiva, basada en las enseñanzas de los Padres de la Iglesia: fundamentalmente San Jerónimo y San Agustín ${ }^{53}$. Algo propio en un tiempo de profundo impacto de la devotio moderna, un pensamiento reformista entendido como el movimiento humanista cristiano que puso el contrapunto al ceremonial repetitivo, la hegemonía de la escolástica y la excesiva superstición enquistada en el credo y el clero católico, propugnando por contra una Fe enraizada en una comunicación más libre e individualizada con la divinidad ${ }^{54}$. En 1536 Francisco de Osuna puso bajo la protección de Cobos su Ley de amor y quarta parte del abecedario espiritual ${ }^{55}$, un autor cuyo libro anterior, el Tercer abecedario espiritual, ha sido considerado una primicia de la mística y antecedente del pensamiento de Teresa de Jesús ${ }^{56}$. Por otro lado, la santa de Ávila es una de las claves para entender este viraje de María de Mendoza. Teresa de Jesús, hundiendo sus raíces en un profundo agustinismo $^{57}$, había sufrido un proceso de despojo de la materialidad hacia una vida dedicada a la militancia religiosa. La monja fue un espejo de rectitud moral y abnegación en el que pronto se reflejó María de Mendoza ${ }^{58}$. Así, junto a sus dos hermanos Bernardino y Álvaro, se aprestó a facilitar las fundaciones de la nueva reforma carmelitana, en una estrategia que los relaciona estrechamente con otras grandes casas nobiliarias castellanas, como los ramos principales del linaje Mendoza o los Velasco, en la protección de nuevas corrientes de reforma espiritual ${ }^{59}$. Los contactos con la mística comenzaron a través de su hermano Álvaro, obispo de Ávila ${ }^{60}$, tal y como Teresa de Jesús reconoció en sus Libro de las Fundaciones $^{61}$. Los tres debieron ser muy insistentes para conseguir que el convento de Valladolid fuese una de las primeras fundaciones de la reforma carmelitana, con pasaje milagroso incluido que excusaba la necesaria dilación del resto de nuevas fundaciones en el que el fallecido don Bernardino se apareció

51 Keniston, 1980, pp. 309 y 314-316. El historiador estadounidense también recoge los versos de Luis Zapata en su Carlo famoso que documentan bien este cambio: "Y ansí alabarte a ti, doña María/De Mendoça, sería dezarte en niebla/Qu'en ser caritativa, amiga y pía/De la viudez tornaste la tiniebla": Ibidem, p. 315.

52 José Ignacio DíAz FernÁndez, "El encierro femenino como ideal: Santa Teresa, Cervantes y dos tratados", en A. Serrano De Haro Soriano y E. Alegre Carvajal (eds.), Retrato de la mujer renacentista, Madrid, UNED, 2012, p. 93.

53 Entre las lecturas que poseía María de Mendoza a su muerte podemos encontrar los escritos de ambos Padres de la Iglesia occidental: entre ellas las Epístolas de San Jerónimo, así como la Ciudad de Dios y las Confesiones del santo de Hipona: RAMIRo RAMíREZ, 2018, p. 54. Sería posible rastrear en la biblioteca de doña María las coincidencias entre las publicaciones que recomienda Santa Teresa y los títulos presentes en su palacio con textos de autores como Fray Alonso de Madrid, pero por su extensión deberá ser objeto de un estudio independiente.

54 Véase Marcel Bataillon, Erasmo y España, México, Fondo de Cultura Económica, 1950 y Massimo Firpo, Juan de Valdés e la riforma nell'Italia del Cinquecento, Roma/Bari, Laterza, 2016.

${ }_{55}$ Francisco De OsunA, Ley de amor y quarta parte del Abecedario spiritual, Burgos, Casa de Juan de Junta Florentino, 1536.

56 Palma Martínez-Burgos García, “Origen de la teoría artística de la Contrarreforma. El Cardenal Tavera y el Concilio Provincial de Toledo en 1536”, en R. Villena Espina, (coord.), Ensayos Humanísticos: Homenaje al profesor Luis Lorente Toledo, Toledo, Universidad de Castilla-La Mancha, 1997, p. 295 y Keniston, 1980, p. 335.

57 "Yo soy muy aficionada a San Agustín, porque el monasterio adonde estuve seglar era de su Orden; y también por haber sido pecador, que en los santos que después de serlo el Señor tornó a Sí hallaba yo mucho consuelo [...] Como comencé a leer las Confesiones, paréceme me veía yo allí”: Teresa De Jesús, Vida de Santa Teresa, Madrid: Apostolado de la Prensa, 1930, p. 69. Es importante este parangón entre la trayectoria vital de ambos doctores de la Iglesia, más allá del uso que hiciese la religiosa de la imagen de San Agustín para mantener una imagen de ortodoxia para su reforma: María Luisa DE LA CÁMARA, "La dinámica del legado augustiniano en Santa Teresa de Jesús (1515-1582), Criticón, nº 111-112 (2011), pp. 25-41.

58 RAMiro RAMírez, 2018, p. 46.

59 Alegre Carvajal, 2014, pp. 25 y 35-38; Pereda, 2004.

60 Bilinkoff, 2014, p. 148 y María Antonia Fernández Del Hoyo, “Los Mendoza: clientes de Juni”, Boletín del Museo Nacional de Escultura, no 10 (2006), pp. 23-30.

61 Teresa DE Jesús, Libro de las fundaciones 10, 6 [en línea], http://www.santateresadejesus.com/wp-content/uploads/LasFundaciones.pdf [Consulta: 25 de marzo de 2017]. 
a la santa en repetidas ocasiones para solicitarle una mayor celeridad en los trámites, pues la primera misa en el nuevo convento libraría su alma del purgatorio ${ }^{62}$.

De este modo, el 15 de agosto de 1568, Teresa junto a otras cinco religiosas acompañadas por San Juan de Ávila tomaron posesión de la huerta y casa que Bernardino de Mendoza había donado a la reforma junto al Pisuerga. Sin embargo, su primera situación fue frágil y, pasados dos meses, la insalubridad de su ubicación junto al río y su lejanía con respecto al centro de la ciudad provocaron la salida de la comunidad y su realojamiento en el palacio de doña María hasta encontrar un nuevo lugar donde fundar el convento ${ }^{63}$.

Gracias a un testimonio directo de la fundación sabemos que las monjas estuvieron allí "con mucho recogimiento sin salir del quarto, y allí oyan missa desde una tribuna que cae a la parroquia" ${ }^{6}$. La necesidad de ese "recogimiento" que evitase las tentaciones y contaminaciones del exterior fue una obsesión para Teresa de Jesús con un profundo impacto en la arquitectura carmelitana de las primeras fundaciones ${ }^{65}$. También provocó hondas huellas en la manera de experimentar y vivir los espacios construidos. La transformación del palacio en convento durante cuatro meses, hasta el 3 de febrero de 1569 cuando las monjas tomaron posesión del nuevo monasterio fundado por doña María en las antiguas casas de María Hernández de la Isla ${ }^{66}$, conmocionó a buen seguro su experimentación sensitiva de la arquitectura y los criterios estéticos de María de Mendoza. Los mensajes de austeridad de la santa se dirigían siempre hacia la necesidad del encierro y a la búsqueda de la adecuada proporción arquitectónica adaptada a la individualidad, ya que entendía que el lugar dedicado a la reflexión desde el que posteriormente produjo las páginas de su literatura estaba también en relación con el medio físico ${ }^{67}$, en concordancia con un movimiento espiritual de oración íntima. Esta declaración explícita contra los edificios amplios y suntuosos contrastaba fuertemente con el palacio de la Corredera de San Pablo y su naturaleza de edificio representativo, antítesis de las propuestas de la religiosa. Una de sus proclamas puede ayudarnos a entender esta contradicción:

¡Oh, válame Dios, qué poco hacen estos edificios y regalos exteriores para lo interior! Por su amor os pido, hermanas y padres míos, que nunca dejéis de ir muy moderados en esto de casas grandes y suntuosas. [...]

Pues sólo de una celda es lo que gozamos continuo; que ésta sea muy grande y bien labrada ¿qué nos va? Sí, que no hemos de andar mirando las paredes ${ }^{68}$.

${ }^{62}$ Para conocer los avatares de las primeras fundaciones de Teresa de Jesús en relación con las primeras benefactoras de la reforma carmelitana, véase Esther Alegre CARVAJAL, "El encuentro y la ruptura entre Teresa de Jesús y la Princesa de Éboli, ¿Una cuestión de enfrentamiento personal o un asunto de estrategia política?", eHumanista, n 24 (2013), pp. 466-478.

63 Apuntes para el historial de la Casa de Camarasa, San Sebastián, Editorial Católica Guipúzcoa, 1934. pp. 96-98; Juan Agapito Revilla, "Estancia provisional de Santa Teresa de Jesús en el palacio del secretario Cobos, en Valladolid", Boletín de la Sociedad Castellana de Excursiones, vol. XII, no 143 (1914) pp. 529-532.

64 Agapito Revilla, 1944, p. 133.

65 Véase Beatriz Blasco Esquivias, "Utilidad y belleza en la arquitectura carmelitana: las iglesias de San José y la Encarnación", Anales de Historia del Arte, no 14 (2004), pp. 143-156.

66 Agapito Revilla, 1944, p. 133. María de Mendoza también facilitó el asentamiento de la rama masculina de la orden con 2.000 ducados -1500 para la compra de la propiedad y otros 500 para comenzar la obra- a cambio del derecho de ser sepultada en su capilla mayor, prerrogativa de la que años después liberó al convento: Ana Cristina VALERo CoLlANTES “Arte e iconografía de los conventos carmelitas de la provincia de Valladolid", Tesis doctoral, Valladolid, 2014, pp. 327-328. Estos contrastes entre arquitecturas de gran significación y edificios de menor entidad reformados para su posterior adaptación a institución religiosas son continuos en las fundaciones teresianas llevadas a cabo por la propia santa. Responden a una voluntad de Teresa por el ejercicio de la restauración que tiene su correlato en su pensamiento nostálgico de un pasado espiritualmente más sano que, bajo su criterio, era posible recuperar a través de un ejercicio salvífico de renovación: María M. CARRIÓN, “Alborada de las ruinas. Teresa de Jesús y la memoria histórica de al-Andalus”, e-Humanista, no 33 (2016), p. 180.

67 CARrión, 2016, p. 178.

68 Teresa De Jesús, Libro de las fundaciones 14, 4 y 5 [en línea], http://www.santateresadejesus.com/wp-content/uploads/LasFundaciones.pdf [Consulta: 25 de marzo de 2017]; citado en DíAz FERNÁNDEZ, 2012, p. 105. 


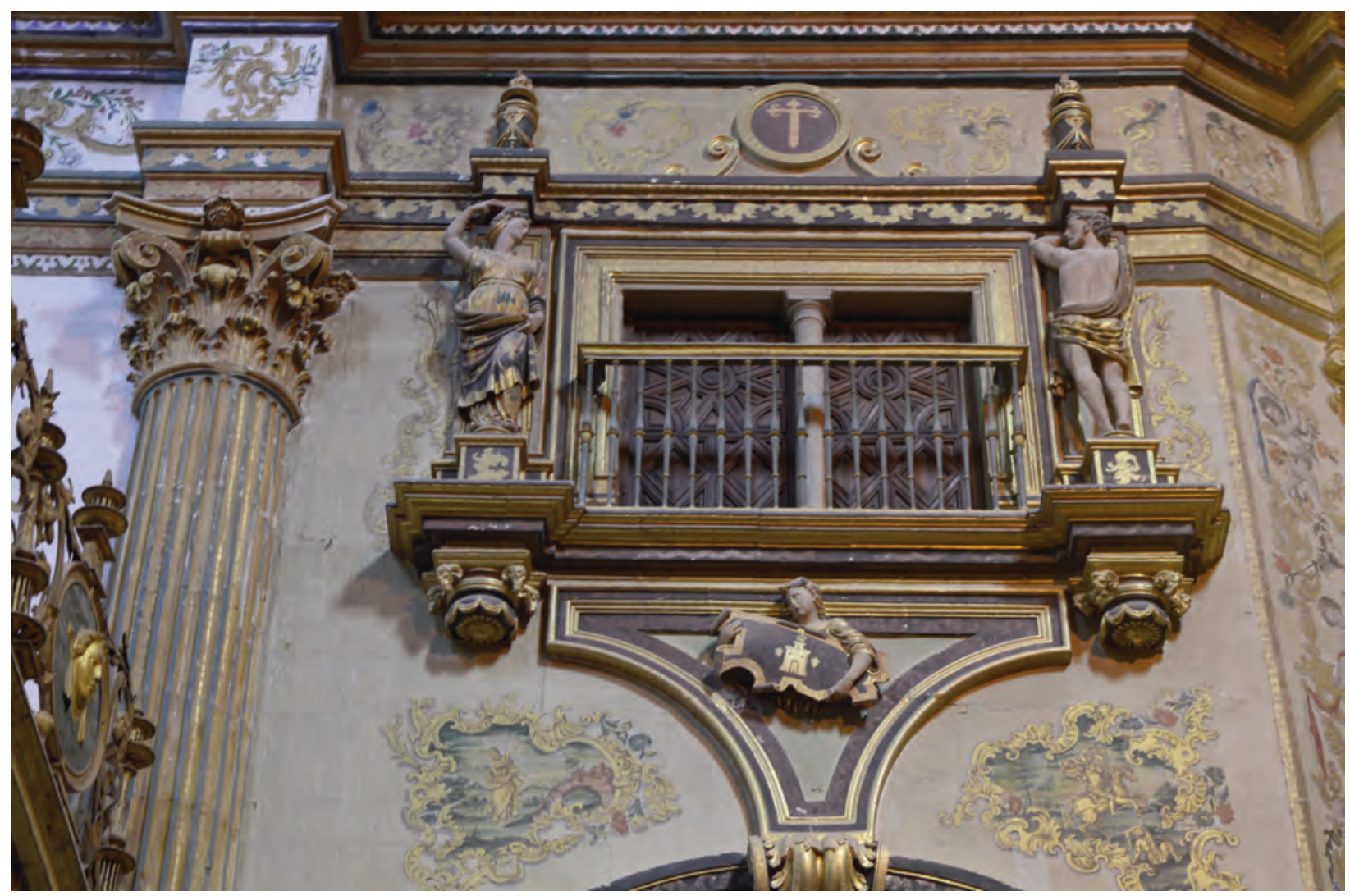

Fig. 5. Andrés de Vandelvira y ¿Julio de Aquiles?, Tribuna en el presbiterio de la Sacra Capilla de El Salvador, ca.1555, Úbeda (Jaén).

Debemos añadir que el pasadizo y la tribuna, este último una ventana al final de un corredor desde el que poder asomarse al espacio sagrado, encajan a la perfección con la idea de recogimiento tan defendida por la reformadora. Ambas constituían la única salida a la iglesia donde la rutina del ejercicio espiritual personal se rompe momentáneamente en favor de la asistencia al culto colectivo en el templo. Santa Teresa lo vuelve a dejar claro en su Libro de las Fundaciones al tratar del convento de la Trinidad de Soria, un cenobio creado gracias a la anexión de las casas de doña Beatriz de Beamonte y Navarra a una parroquia colindante. A su llegada, las monjas celebraron la primera misa en un salón de la residencia, hasta que pudo hacerse el pasadizo a la iglesia: "y dejonos en aquel cuarto, adonde estuvimos recogidas, hasta que se hizo el pasadizo, que duró hasta la Transfiguración"69.

En mi opinión, esa nueva vinculación del encierro y la importancia del pasadizo y tribuna explica por qué en 1576, casi veinte años después de la consagración de la Sacra Capilla de El Salvador de Úbeda, María de Mendoza mandó construir uno nuevo que la condujese desde su palacio ubetense hasta una tribuna situada en la capilla mayor (fig. 5). Sabemos que el 23 de octubre de ese mismo año ordenó a los capellanes de su iglesia acelerar las obras para poder utilizarlas lo antes posible ${ }^{70}$. No he podido saber, por

69 Ibidem, 30, 1-9.

70 "lo questa conçertado para haçer esos pasadiços desseo se acave que espero en dios he de ir presto a aprovecharme dellos. $\mathrm{Y}$ entre tanto quería lo hiçiesen y a su señoria dad la priessa a los que tienen a cargo de ello que de otra suerte nunca se effectuaria": "Carta de María de Mendoza a los capellanes de la Sacra Capilla de El Salvador de Úbeda", AGA, Documentos andaluces de la Casa Ducal de Medinaceli, Sacra Capilla de El Salvador 283/363-418, Microfilm 015-002, Carta 32. 


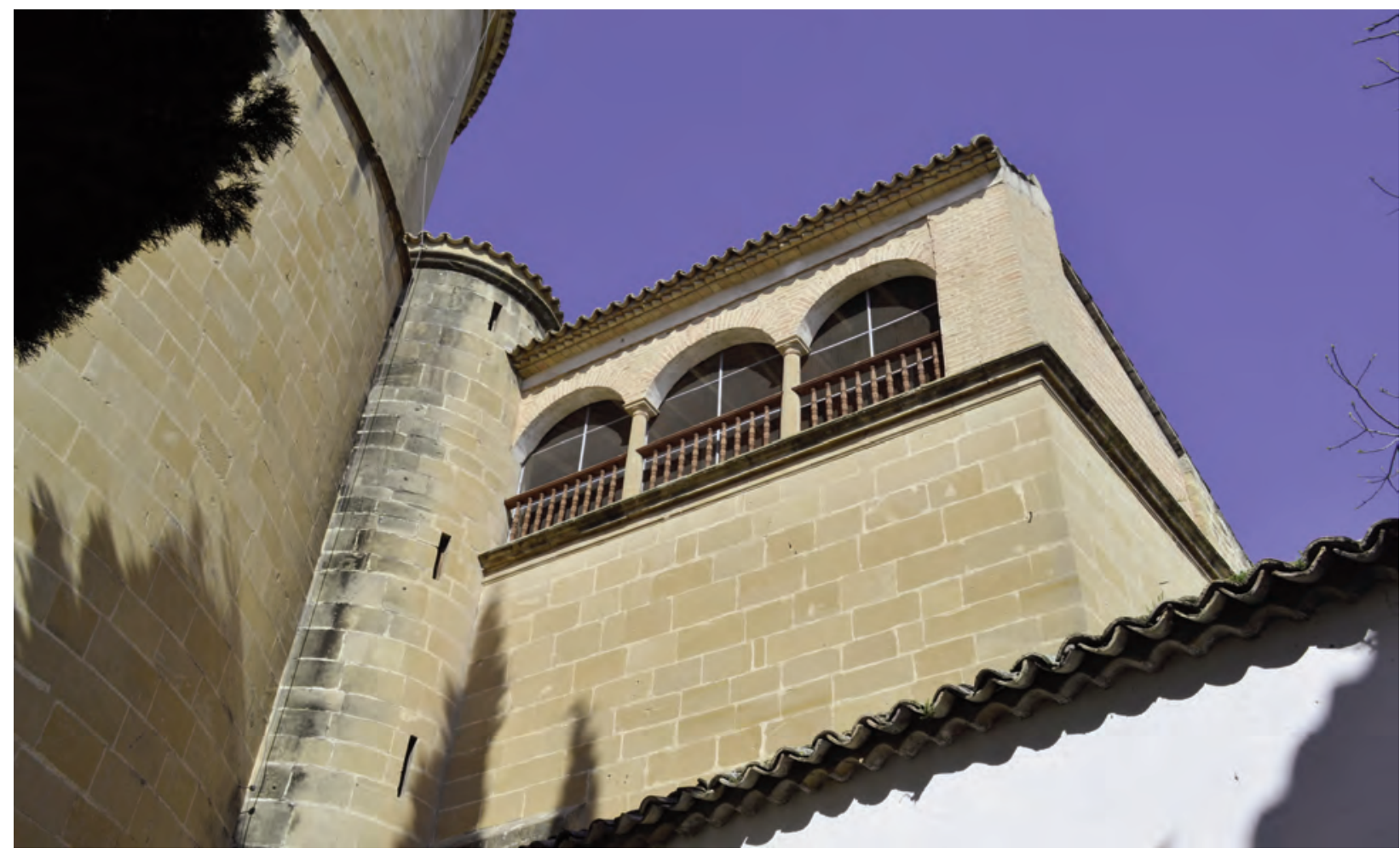

Fig. 6. Andrés de Vandelvira, Escalera de caracol entre la capilla mayor y la sacristía de la Sacra Capilla de El Salvador, 1540-1555, Úbeda (Jaén).

la imposibilidad de reconocer el conjunto palacial original y su conexión con el templo, cómo pudo formalizarse este recorrido. Por un lado, existía una escalera de caracol en un patinejo entre la iglesia, el Hospital de los Honrados Viejos de El Salvador y la residencia, que permitía alcanzar las estancias sobre la sacristía ${ }^{71}$ (fig. 6) y, quizá por esta vía, acceder a la tribuna. Por otro lado, también es posible que la conexión se realizase a través de las denominadas casas de los Herrera, posteriormente transformadas en "Cátedra de Retórica y Gramática por doña María en el año 1570", situadas entre su residencia y el templo (fig. 7) ${ }^{72}$. Además de la obvia comodidad que suponía para la ya anciana María de Mendoza, es posible concluir que con el paso del tiempo restringió voluntariamente la exposición de su imagen y todos los edificios de su titularidad se debían preparar para satisfacer su deseo de recogimiento.

\section{Vivir en convento como una duquesa: María Sarmiento funda Nuestra Señora de la Piedad de Granada}

El comportamiento durante la viudedad de María de Mendoza fue un modelo para su única hija. Tras su matrimonio, María Sarmiento se trasladó a Baena donde pasó la mayor parte de su vida administrando

71 Casi un siglo más tarde se abrió un pórtico de ladrillo que permitía también la comunicación entre la sacristía y el patio: AGA, Documentos andaluces de la Casa Ducal de Medinaceli, Sacra Capilla de El Salvador 267/213-620, Microfilm 002-001, Libros de Actas Capitulares de la Sacra Capilla de El Salvador de Úbeda, Año 1667, fol. 165r.

72 "Carta de doña María de Mendoza a los capellanes de la Sacra Capilla de El Salvador a 4 de abril de 1570", AGA, Documentos andaluces de la Casa Ducal de Medinaceli, Sacra Capilla de El Salvador, 283/363-418, Microfilm 015-002, Cartas y órdenes del marqués de Camarasa a la capilla del Salvador, Carta 59. 


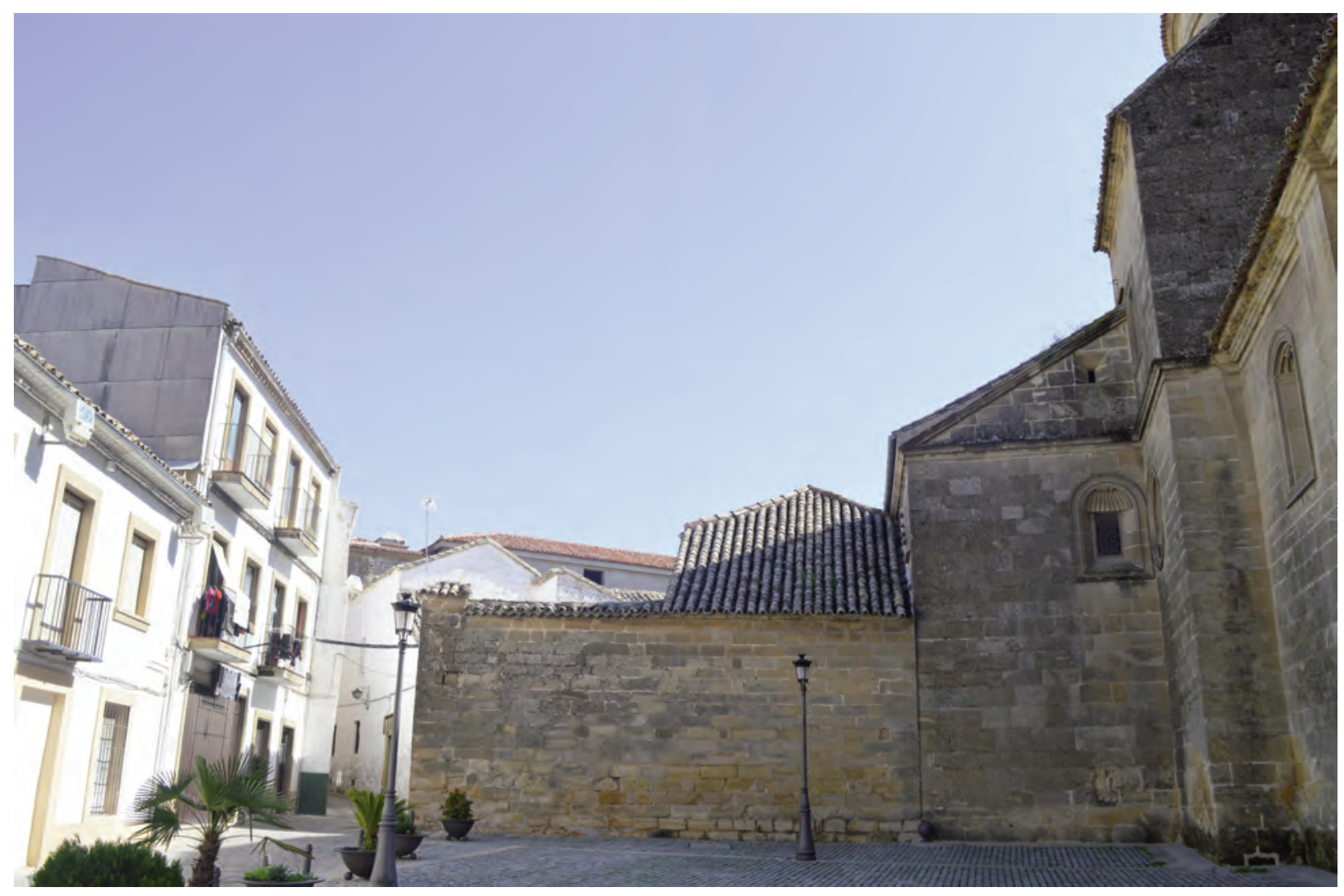

Fig. 7. Punto de unión entre la Casa de los Herrero y la Sacra Capilla de El Salvador junto a su fachada norte, 15401555, Úbeda (Jaén).

las posesiones familiares mientras su marido servía militarmente a Felipe II en Italia y España. A la muerte del duque sin descendencia, retornó al palacio vallisoletano de sus padres, donde había pasado su niñez y adolescencia, y donde moró hasta la muerte de su madre el 11 de febrero de 1587. En su lecho de muerte, María de Mendoza donó todos los bienes de palacio a su hija ${ }^{73}$ quien se trasladó al sur, más concretamente a Granada, para residir durante el resto de sus días. Allí fundó en 1589 el convento de religiosas dominicas de Nuestra Señora de la Piedad (fig. 8), en unas casas que había comprado por nueve mil ducados al jurado Valladolid ${ }^{74}$. El cenobio aún existe en su emplazamiento cercano a la iglesia de San Jerónimo, panteón familiar de los Sesa, y su título de duquesa aún da nombre a la calle granadina en la que se encuentra. Alejada de la corte y de los territorios señoriales de la familia de su marido, María Sarmiento encontró en el monasterio de la Piedad un lugar en el que administrar su propio patrimonio, amenazado por las pretensiones de su sobrino el marqués de Camarasa ${ }^{75}$, donde pudo ejercer el patronato y administración de una comunidad. Por otro lado, los ejemplos de cohabitación entre palacio e institución religiosa fueron habituales en la labor de patronazgo de sus familias biológica y política. La duquesa conoció bien la labor de los abuelos de su marido, María Manrique y Gonzalo Fernández de Córdoba el Gran Capitán, en el monasterio granadino de San Jerónimo. En las capitulaciones redactadas en 1525 para el entierro de los duques

73 RAMiro RAMírez, 2018.

74 Manuel Gacía LuQue, "El convento granadino de La Piedad, de religiosas dominicas: notas de historia y arte", EntreRíos, $\mathrm{n}^{\mathrm{o}}$ 21-22 (2014), p. 171.

75 RAMIRO RAMÍREZ, 2018. 


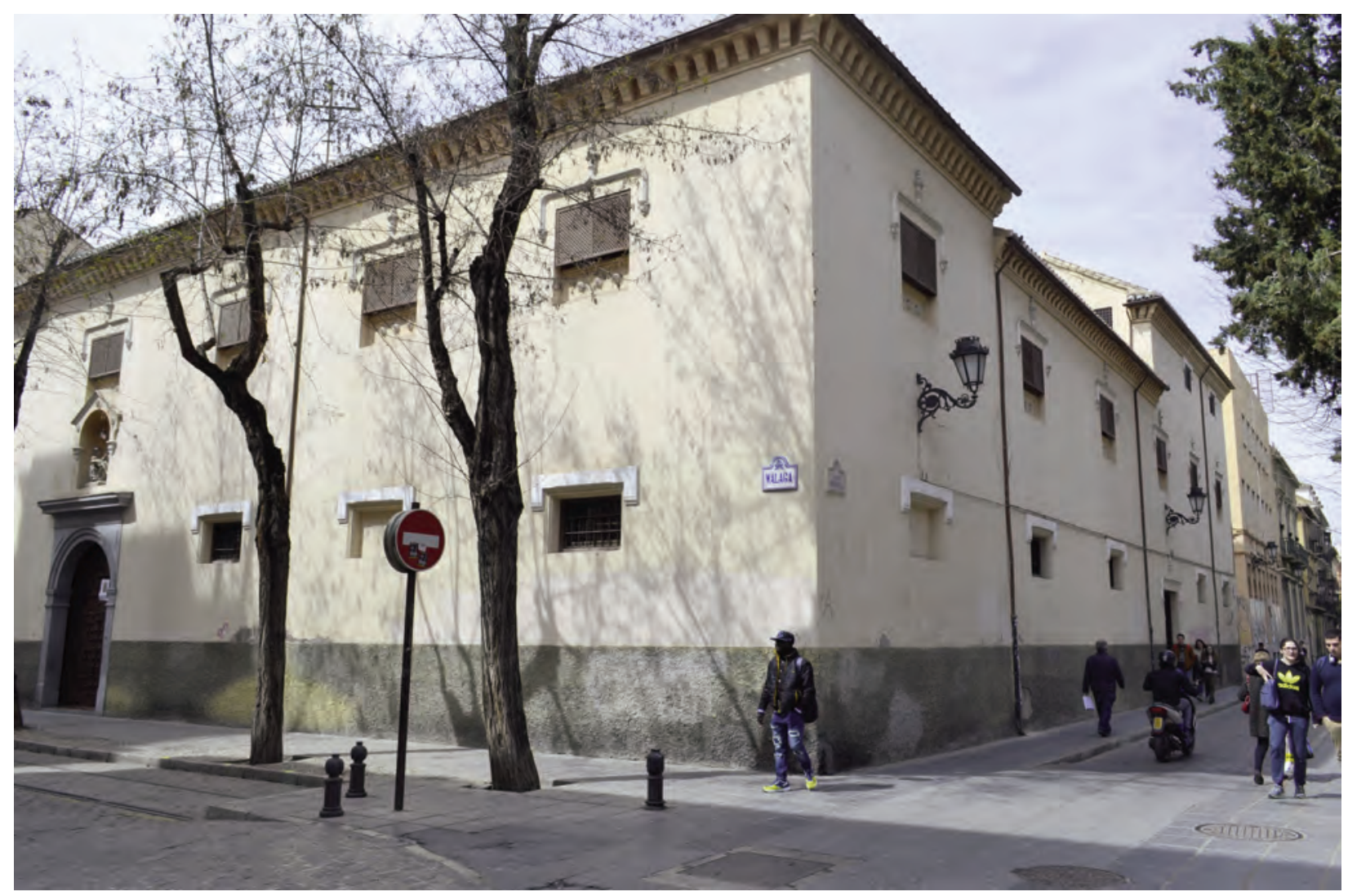

Figura 8: Convento de Nuestra Señora de la Piedad, 1589, Granada.

en el presbiterio de la iglesia jerónima, María Manrique había defendido su derecho a tener una casa dentro del cenobio, en el lugar que a ella le pareciere más a propósito, con una tribuna que enlazase su residencia directamente con la iglesia. El derecho a beneficiarse de la estructura era exclusivo y vitalicio y su acceso se realizaría a través de un pasadizo y una escalera de caracol interna ${ }^{76}$.

En el convento de San Jerónimo estaba también previsto el entierro de María Sarmiento junto al cuerpo de su esposo ${ }^{77}$, por tanto, la duquesa estaba al tanto de estos proyectos. Asimismo, existían a su alcance otros ejemplos de cohabitación en fundaciones cercanas a sus señoríos. También en 1525, María de Luna, hermana menor de Catalina Fernández de Córdoba duquesa de Priego fundó, junto al palacio de su hermana, el convento de Santa Clara de Montilla en el que ingresó con el nombre de Sor María de Jesús,

76 "La señora duquesa pueda mandar haceros haga ( $\mathrm{sic}$ ) aposento para su persona o estados dentro de la cerca de la huerta del dicho monasterio o donde era primero o en la huerta del o en la parte de estas que más conveniente le pareciere e quisiere. A que de donde fuere el dicho aposento ha de abertura pasadizo hasta la dicha Capilla con tribunal con un caracol que abaje a la dicha Capilla a la parte que mejor le pareciere. Y esto se entiende que ha de durar el dicho pasadizo y tribuna y caracol solamente por los días y vida de la dicha señora duquesa y no más": "Capitulaciones de María Manrique con el monasterio de San Jerónimo de Granada para el enterramiento familiar en la capilla mayor de la iglesia”, AHN, Clero-Regular Secular, Libro 3881, s/f. El palacio de los Fernández de Córdoba poseía otro pasadizo que comunicaba la residencia con el convento de San Francisco a través del cual se trasladó el cadáver de doña María tras su muerte en 1527: Nuria MARTínEz JimÉnEz, "María Manrique de Lara. La duquesa y la introducción del Renacimiento italiano en Granada", Atrio. Revista de Historia del Arte, 21 (2015), p. 52.

77 "Testamento de María Sarmiento, duquesa de Sessa", AGA, Documentos de la Casa Ducal de Medinaceli, Sabiote y otros señoríos de la casa de Camarasa en el Reino de Jaén, Microfilm 002-008 n² 2, fol. $15 \mathrm{r}$. 


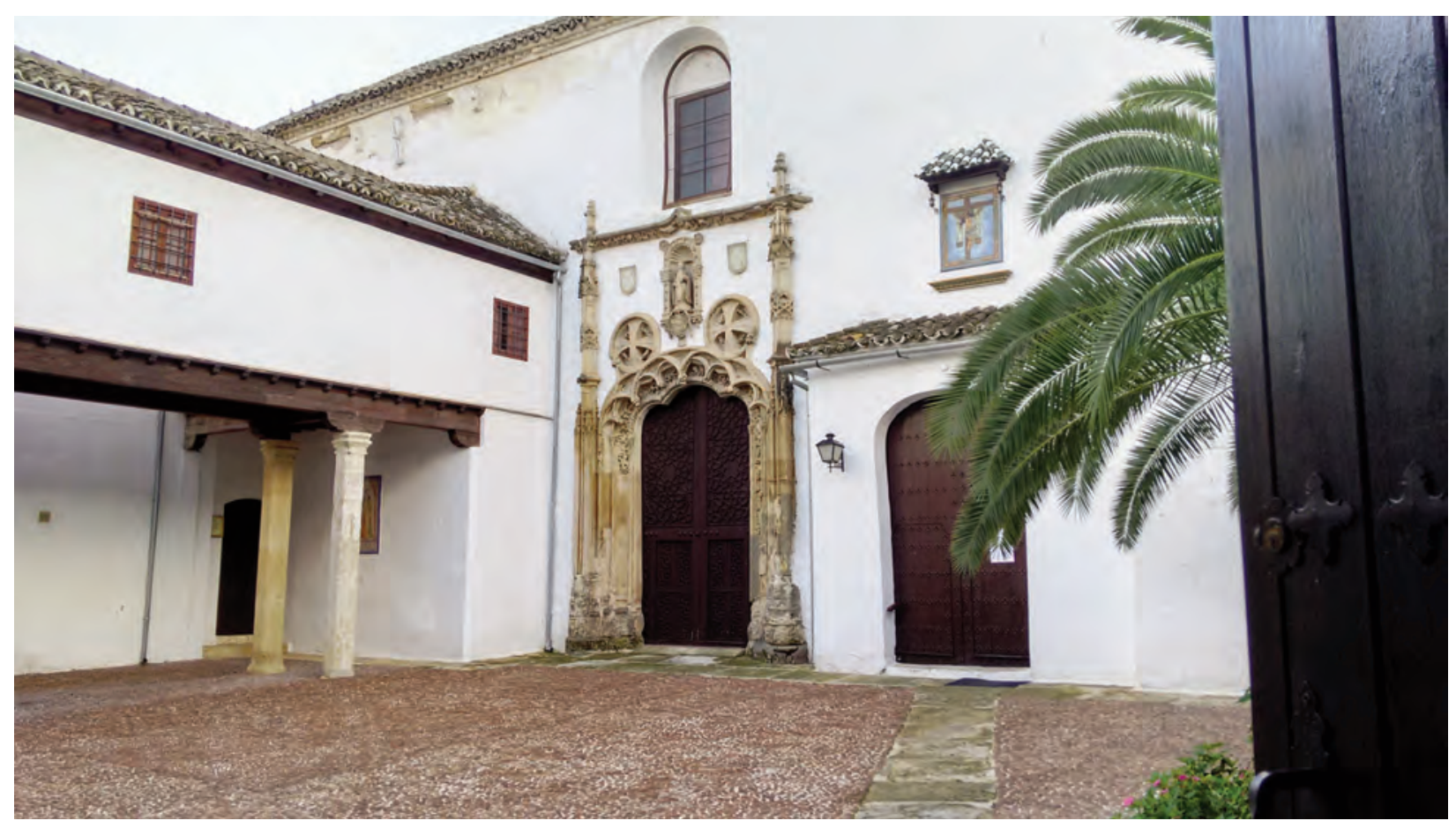

Fig. 9. Pasadizo en alto entre el palacio de la marquesa de Priego y la iglesia del Convento de Santa Clara de Montilla, a partir de 1544, Montilla, Córdoba.

y en 1544 la duquesa de Priego obtuvo una bula penitenciara para construir un pasadizo que comunicase su residencia con la iglesia. Aún hoy la galería volada y cerrada discurre por encima del Arco de Santa Clara -situado entre el palacio y el convento- y sigue su recorrido dentro de la clausura por uno de los laterales hasta alcanzar el lado izquierdo de la cabecera del templo (fig. 9) ${ }^{78}$.

Según refirió Gómez Moreno-Calera, de la configuración original del convento de la Piedad solo tenemos una imagen muy aproximada representada en la Plataforma de Vico (Fig. 10), pues sus exteriores fueron profundamente reformados en el siglo XIX a excepción de una torre con muestras de columnas y ventanas acodadas existente en su costado oeste. Asimismo, aún se conserva en su interior el patio del siglo XVI con arcos de medio punto moldurados y ménsula geométrica sobre columnas toscanas, del que parte la escalera principal cubierta con una armadura ochavada decorada de lazo, piña de mocárabes en el almizate y policromada ${ }^{79}$.

En los capítulos fundacionales del convento dominico de Nuestra Señora de la Piedad, María Sarmiento también se reservó el derecho de abrir "una puerta de mi aposento a el convento para que yo pueda entrar a el las veces que me pareciere" 80 . Por su testamento, firmado a 18 de enero de 1604, tenemos más datos

$78 \mathrm{Su}$ residencia y la de su familia terminaron por extenderse también al monasterio, ya que la duquesa pasó algunas temporadas con sus hermanas, María e Isabel que también ingresaron en el convento; así como con su nuera Ana Ponce de León. Esta última también poseía un pasillo que enlazaba sus aposentos con una tribuna en el presbiterio del templo. Por último, doña Catalina construyó una residencia para su hermana Teresa Enríquez que terminaron englobadas dentro de la clausura, a cambio de darle alojamiento, nada más y nada menos, que en el claustro del convento: ARANDA BERNAL, 2015, pp. 259-263.

79 José Manuel Gómez-Moreno CALerA, La arquitectura religiosa granadina en la crisis del Renacimiento, (1560-1650): Diócesis de Granada y Guadix-Baza, Granada, Universidad de Granada/Diputación Provincial de Granada, 1989, p. 241.

80 "Capítulos fundacionales del Monasterio de Nuestra Señora de la Piedad de Granada", AHN, Clero-Regular_Secular, Libro 3881 , fol. $87 \mathrm{v}$. 
sobre la disposición de sus casas en relación con la vida del cenobio. María Sarmiento disfrutó de un cuarto junto al altar mayor de la capilla que debía estar siempre a disposición del patrón del monasterio para oír las misas y sermones. Su posición en relación con la iglesia fue el punto en el que orbitó toda la arquitectura y cualquier modificación sobre la situación del templo debía de tener en cuenta siempre la existencia de dicho derecho:

Y es mi voluntad que toda la dicha pieza según que es de presente esta es con la dicha rejas derecho de tenerla y asistir en ella y oir misa e sermones [...] Que siempre este como esta para que desde allí puedan los dichos patrones o personas que ellos quisieren oir misa e sermón todas las veces que quisieren e para la entrada a ella mando que por la sacristía por la calle se hace la puerta conveniente para que por ella se pueda entrar en la tal pieza para el dicho efecto y este cerrada y la llave de la dicha pieza e reja este en poder del patrón [que] es o fuese para siempre jamas e se acabe de mudar el altar mayor

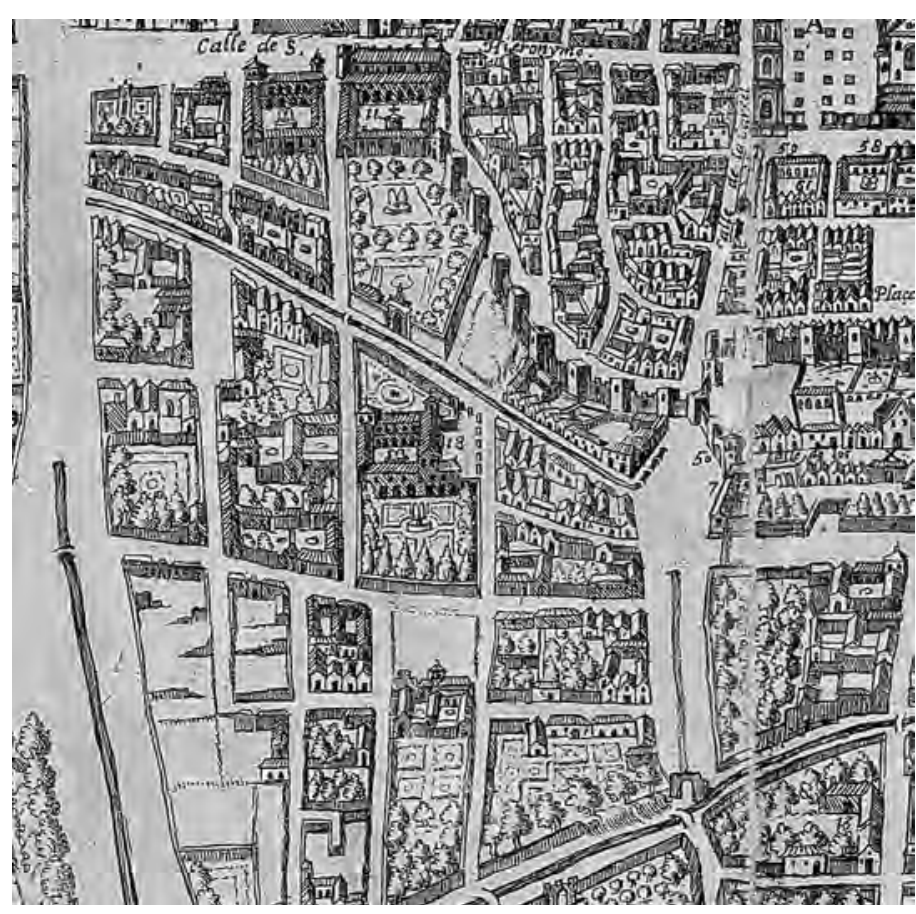

Fig. 10. Ambrosio de Vico y Francisco Heylan, Vista de la ciudad de Granada, [Detalle] ca. 1613, Madrid, Biblioteca Nacional de España, MV/12. El palacio está señalado en la vista con el número 18.

della a su sitio e lugar donde oy esta o la iglesia a se agrandar e dar en dicho gravamen e preminencia con que el dicho aposento se le de a los patrones del mismo tamaño y en el propio lugar que el agora esta respetivamente de manera que siempre aya un aposento de aquel tamaño y hechura al lado del altar mayor e junto como agora esta e dentro de la capilla mayor de manera que puedan como oir misa e sermón desde la tal ventana y que el pulpito se ponga siempre frontero della para que puedan bien oir el sermón porque para este efeto se hizo e asi quiero que permanezca perpetuamente $[\ldots]^{81}$.

Como hemos avanzado, la fundación de un establecimiento religioso manteniendo un cuarto anexo permitía a la duquesa asegurar la administración y agencia sobre una comunidad sin necesidad de tomar los hábitos. Además, a través de la capitulación fundacional y su testamento, la duquesa consigue hacer prevalecer sus necesidades a las del convento, obligando a tener bien en cuenta la posición privilegiada del patrón para el disfrute desde su residencia de los oficios divinos.

María Sarmiento, sin embargo, tuvo muy presentes los problemas de interacción entre el próximo patrón, su sobrino Diego Sarmiento de los Cobos, deán de la Catedral de Córdoba, y las religiosas. Para ello, mandó hacer el respectivo pasadizo que le permitiese acudir a la iglesia sin ser vista y no olvidó hacer una recomendación a su sobrino Diego sobre el respeto al recogimiento de las monjas, así como la debida buena vecindad.

El dicho aposento hasta llegar al pasadizo por donde se entra a la otra casa en que vive el conde don Diego mi sobrino que esta oy incorporada con esta porque el pasadizo a de quedar [...] Y [queda encargado] de la visitaxion de las monjas del dicho monasterio para que tengan buena vecindad a su gusto y [...] le encargo al dicho

\footnotetext{
81 "Testamento de María Sarmiento, duquesa de Sessa”, AGA, Documentos andaluces de la Casa Ducal de Medinaceli, Sabiote y otros señoríos de la casa de Camarasa en el Reino de Jaén 464/008-167, Microfilm 002-008 n 3, fols. 57r-58v.
} 
conde don Diego de los Cobos les atienda e haga toda buena vecindad e comodidad como a gente tan santa e recogida e quien tanto amor he recibido e tengo yo ${ }^{82}$.

Unas frases que nos devuelven el sentido del patronato como el ejercicio de la protección sobre la religiosa amparada, otra estrategia de diferenciación social, y no tan solo como acción de autopromoción social. Por otro lado, es muy esclarecedor que María Sarmiento recuerde el modelo de mujer "santa" como mujer "recogida". Para conseguir ese fin, la arquitectura jugó un papel fundamental en el mantenimiento de la estricta regla de clausura impuesta en la segunda mitad del siglo XVI. La ventana que unía la residencia seglar con la comunidad religiosa permitía asomarse a esa realidad conventual desde sus propios cuartos cumpliendo con el retiro perfecto para una mujer que había desarrollado su vida en la corte ejerciendo su papel de consorte y ahora mantenía el honor de su nombre a través del patronato religioso. Ambos modelos de vida quedaban, eso sí, mutuamente influidos por la comunicación física que permitía la construcción de estos elementos arquitectónico de unión. La duquesa vivió, como su madre, su clausura particular junto a las religiosas, aunque sin ocupar físicamente su espacio. El pasadizo y vano junto al altar mayor se lo permitía. Por otro lado, las monjas hubieron de mantenerse siempre bajo la atenta contemplación de los sucesivos patronos del monasterio y no pudieron componer la disposición arquitectónica del convento según su criterio, pues hubo de orbitar en torno a la mirada privilegiada del seglar ${ }^{83}$.

SERGIO RAMIRO RAMíREZ es Doctor internacional en Historia del Arte por la Universidad Complutense de Madrid (2018) con la tesis "Patronazgo y políticas artísticas en la corte de Carlos V: Francisco de los Cobos y Molina". También ha sido becario en la Fondazione di Studi di Storia dell'Arte Roberto Longhi de Florencia (2013/2014) e Investigador Predoctoral en Formación FPU del Ministerio de Educación Cultura y Deporte (2014). Asimismo, ha disfrutado de una beca de alojamiento en la Residencia de Estudiantes de Madrid financiada por el Ministerio de Economía y Competitividad (2016/2017). Actualmente es colaborador honorífico en el Departamento de Historia del Arte de la Universidad Complutensede Madrid, miembro del proyecto "Femenino singular. La mujer y las Artes en la Corte española en la Edad Moderna (reinas, nobles, artistas y empresarias)" (HAR2015-65166-P), así como del grupo de investigación reconocido UCM (971718) "La corte española: arte, artistas y mecenas".

Email: serramir@ucm.es

\footnotetext{
82 Ibidem, fols. $59 \mathrm{v}$ y $62 \mathrm{r}$.

${ }^{83}$ Este artículo forma parte de los resultados obtenidos gracias al proyecto $\mathrm{I}+\mathrm{D}+\mathrm{i}$, financiado por el Ministerio de Economía y Competitividad y el Fondo Europeo de Desarrollo Regional, HAR2015-65166-P (MINECO/FEDER) "Femenino singular: La mujer y las artes en la corte española en la Edad Moderna (reinas, nobles, artistas y empresarias)". Asimismo, su elaboración ha sido posible gracias a la Ayuda de Formación del Profesorado Universitario del Ministerio de Educación, Cultura y Deporte con la que realizo mi tesis doctoral, en curso, titulada «Francisco de los Cobos y Molina (ca.1477-1547) y las artes» y una beca de alojamiento en la Residencia de Estudiantes de Madrid comenzada en diciembre de 2016 y financiada por el Ministerio de Economía y Competitividad.
} 